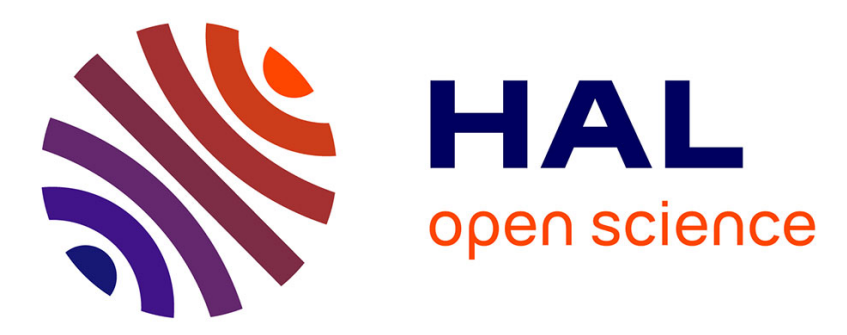

\title{
Improvement of the solute transfer in a conceptual unsaturated zone scheme: a case study of the Seine River Basin
}

Florence Habets, Emmanuel Ledoux, Patrick Goblet, Pascal Viennot, Bruno Mary

\section{To cite this version:}

Florence Habets, Emmanuel Ledoux, Patrick Goblet, Pascal Viennot, Bruno Mary. Improvement of the solute transfer in a conceptual unsaturated zone scheme: a case study of the Seine River Basin. Hydrological Processes, 2010, 25 (5), pp.752-765. 10.1002/hyp.7865 . hal-00507039

\section{HAL Id: hal-00507039}

https://hal-mines-paristech.archives-ouvertes.fr/hal-00507039

Submitted on 29 Jul 2010

HAL is a multi-disciplinary open access archive for the deposit and dissemination of scientific research documents, whether they are published or not. The documents may come from teaching and research institutions in France or abroad, or from public or private research centers.
L'archive ouverte pluridisciplinaire HAL, est destinée au dépôt et à la diffusion de documents scientifiques de niveau recherche, publiés ou non, émanant des établissements d'enseignement et de recherche français ou étrangers, des laboratoires publics ou privés. 


\title{
Improvement of the solute transfer in a conceptual unsaturated zone scheme: a case study of the Seine River Basin
}

\author{
Elodie Philippe ${ }^{\mathrm{a}, 1, *}$, Florence Habets ${ }^{\mathrm{b}}$, Emmanuel Ledoux $^{\mathrm{a}}$, Patrick Goblet ${ }^{\mathrm{a}}$, \\ Pascal Viennot ${ }^{\mathrm{a}}$, Bruno Mary ${ }^{\mathrm{c}}$ \\ ${ }^{a}$ Mines Paristech, Geosciences Center, 35 rue St Honoré, 77305 Fontainebleau, France \\ ${ }^{b}$ CNRS/UPMC UMR Sisyphe, Paris, France \\ ${ }^{c}$ INRA, Agronomical Unit, rue F. Christ, 02007 Laon Cedex, France
}

\begin{abstract}
For predicting the evolution of solute concentrations in groundwater and testing the impact of remediation policies, a coupling between the agronomical model STICS and the hydrogeological model MODCOU was implemented. Applied to the Seine river basin, this model represents accurately the temporal evolution of average nitrate concentrations in the aquifer, but with large local errors.
\end{abstract}

We propose an improvement of the simple unsaturated zone scheme NonsatSW used in STICS-MODCOU. The modifications are based on a comparison with the mechanistic model Metis considered as a reference as it solves Richards' equation. A more realistic saturation profile and a varying percolation rate are integrated in NonsatSW. This new model, named NonsatVG, is assessed

\footnotetext{
${ }^{*}$ Corresponding author

Email address: elodie.philippe@mines-paristech.fr (Elodie Philippe)

${ }^{1}$ Tel: +331-64-69-47-47, Fax: +331-64-69-47-03
} 
by a comparison with NonsatSW and Metis. In an ideal case, NonsatVG generates a solute transfer and a dispersion closer to that of Metis than NonsatSW. In real cases, without additional calibration, NonsatVG and Metis simulate better the average transfer velocities of the observed nitrate profiles.

Furthermore, modifications in NonsatVG give a direct link between the water table depth and the saturation profile. We obtain therefore, as in Metis, an evolution of the solute transfer velocity depending on the piezometric level. These dynamics are not simulated in NonsatSW.

Despite a modified water transfer through the unsaturated zone, NonsatVG is also as valid as NonsatSW in the modelling of water transfer to the saturated zone.

Finally, an application on the Seine basin show that solute transfer velocities are lower with NonsatVG than with NonsatSW, but in better agreement with literature.

Keywords: unsaturated zone, hydrogeological modelling, solute transfer, nitrate contamination

\section{Introduction}

Since the mid 1950's, fertilizers and phytosanitary products have been used extensively for agricultural purposes. Such practices have led to an increasing diffusion of pollutant in aquifers. The Water Framework Directive (\#2000/60/EC) adopted by the European Commision requires all ground- 
water bodies to achieve a good status by 2015. This goal includes nitrate limit of $50 \mathrm{mg} . \mathrm{L}^{-1}$ set by the Nitrate Directive (91/676/EEC). However, this threshold is already exceeded in many groundwater bodies in Europe, as noted by Rivett et al. (2008). In order to adopt efficient policies regarding agricultural practices and water quality, integrated water models are used to support the decision-making (Refsgaard, 2002; Flipo et al., 2007; Ledoux et al., 2007; O'Shea and Wade, 2009; Sohier et al., 2009).

In the STICS-MODCOU model (Gomez et al., 2003; Ledoux et al., 2007), the agronomical model STICS (Brisson et al., 1998) is used together with the hydrogeological model MODCOU in order to estimate the nitrate contamination in surface and groundwaters. The model was first set up over the Seine basin $\left(78650 \mathrm{~km}^{2}\right)$ in northern France. This basin is characterised by an intensive agriculture and, as it encompasses the Paris urban area, a high density of population and a significant industry. Important works were done to collect the agricultural data, e.g. crops rotation and agricultural practices (Mignolet et al., 2007).

The STICS-MODCOU model is able to represent the temporal evolution of the average nitrate concentration in the aquifer, but some large local errors persist (Ledoux et al., 2007). In order to improve this modelling, special attention is given to the representation of the unsaturated zone in the MODCOU model. The unsaturated zone (UZ) is responsible for the delay for nitrate to reach the water table. This delay can be rather long depending on the UZ thickness and its geological nature. Indeed, the nitrate transfer 
velocity varies for example from 2.50 m.year ${ }^{-1}$ in eroded granite (Legout et al., 2007) to a value as low as 0.60 m.year ${ }^{-1}$ in chalk (Serhal et al., 2006; Gutierriez and Baran, 2009). Therefore, a good estimation of the transfer through the UZ is required to be able to study the impact of nitrate control policies (O'Shea and Wade, 2009; Sohier et al., 2009). The UZ is a polyphasic zone (water, air and solid) where phase changes can occur, as well as physicochemical exchanges between phases due to mechanical and thermal energy variations (Vauclin, 1993). These modifications can influence the dynamics of solute in the UZ. However, the nitrate transfer phenomenology in the UZ can be simplified assuming that most bio-physico-chemical reactions occur in the pedological area (Baran et al., 2007). Thus, although some physically-based models take into account the reactions through the entire hydrosystem, e.g. SHETRAN (Birkinshaw and Ewen, 2000), it is more often considered that no reaction occurs during the transfer of nitrate through the UZ as in MIKE SHE, SWAT and EPIC (Refsgaard et al., 1995; Neitsch et al., 2005; Sohier et al., 2009). We also assume a passive nitrate transfer through the UZ. As MODCOU is devoted to be applied on large scale basins, it is not a fully physically-based model. The flow in the UZ is modelised with a simple cascade reservoirs scheme (Besbès and de Marsily, 1984) based on the Nash Cascade principle (Nash, 1960). This model was extended by Gomez et al. (2003) to allow the transfer of a passive contaminant. This simple model shares some specific features with recently developed UZ models. For instance, EPIC (Sohier et al., 2009) also uses several reservoirs to reproduce 
the unsaturated zone, while Jackson et al. (2006) developed a model for chalk which uses a piston flow mechanism with a constant velocity transfer for water.

To evaluate this UZ module, a comparison with the physically-based model Metis (Castro et al., 2005; Goblet, 2007) was carried out on both ideal and real cases. Indeed, since Metis solves Richards' and convection-dispersion equations using a finite-element method, we assume that it is a reference for our UZ module in these comparison tests. Results show some discrepancies, leading to a modification of the conceptual model.

Both UZ models are presented in section 2. Assessment test results in ideal and real cases are discussed in section 3. An application over the Seine basin is presented in section 4 .

\section{UZ model description}

Two models are used in this study: the mechanistic model Metis, based on the resolution of the Richards' and convection-dispersion equations, and the conceptual model Nonsat.

\subsection{Nonsat model}

Nonsat is a conceptual model simulating the vertical transfer through the UZ. The UZ is assimilated to a series of reservoirs. The original version of Nonsat deals only with water transfer (NonsatW). This version was modified by Gomez et al. (2003) to include the transfer of conservative so- 
lute (NonsatSW, Gomez et al. (2003); Viennot et al. (2006)). This model combines piston flow and some interlayer mixings.

\subsubsection{Modelling of water transfer with NonsatW}

By studying the relationship between soil infiltration and groundwater supply at regional scale, Besbès and de Marsily (1984) showed that the water transfer function in the UZ is comparable to a Nash reservoir cascade (Nash, 1960). The water transfer through the UZ is therefore assimilated to a series of $\mathrm{N}$ reservoirs $i$ of same thickness, flowing in each other. The drainage of each reservoir follows an exponential law. Figure 1 presents the Nash cascade principle. It shows the effect of the cascade on an impulse input. The continuity of flow between reservoirs $i$ and $i+1$ is written:

$$
\operatorname{Vin}_{i+1(t)}=\operatorname{Vout}_{i(t)}=\operatorname{Vol}_{i(t)} \times \delta
$$

with $V i n_{i+1}$ the inflow into reservoir $i+1\left(\mathrm{~m}^{3}\right)$, Vout $t_{i}$ the outflow of water from the reservoir $i\left(\mathrm{~m}^{3}\right), \mathrm{Vol}_{i}$ the volume of water in the reservoir $i\left(\mathrm{~m}^{3}\right)$, $\delta$ a drainage coefficient, $i$ the reservoirs index ranging from 1 to $N$, and $t$ the current time step $(\mathrm{s}) . \quad \delta$ is linked to a percolation time $\tau(\mathrm{s})$ by the relationship $\delta=1-\exp \left(\frac{-d t}{\tau}\right)$ with $d t$ the computation time step (86400 s). The water transfer is therefore based on the drainage of the water volume in the reservoirs, without any storage. Thus, it can be considered that NonsatW deals only with gravitational water.

NonsatW requires only two parameters: $\tau$, that is set according to the soil 
type, and $N . N$ is set depending on the average thickness of the UZ and the given depth of the reservoir (Besbès and de Marsily, 1984). A deeper UZ is simulated by adding some reservoirs, water will therefore take longer to flow through the UZ. This can be compensated by a decrease of $\tau$. Thus, an equivalent velocity transfer can be obtained with different sets of parameters, but the flow is different.

\subsubsection{Modelling of the water and passive solute transfer with NonsatSW}

NonsatW was modified by Gomez et al. (2003) to manage passive solute transfer.

Solute transfer needs to explicitly manage the whole water volume in the UZ, that is to say the gravity water already taken into account in NonsatW, but also the capillary water retained in small pores. Indeed, this immobile phase contributes to solute storage in the UZ. Therefore, Gomez et al. (2003) introduced a minimal volume $\mathrm{V}_{\min }$ that represents the water retained in the UZ. $\mathrm{V}_{\min }$ is set identical in all the reservoirs $i$ of an UZ column.

In order to limit mixing within the whole reservoir, Gomez et al. (2003) also introduced a stratification (Figure 2). When infiltration occurs at a time step, a stratum $j$ is introduced at the top of the UZ. Strata $j$ in each reservoir $i$ are defined by a given water volume and a given concentration depending on pedo-climatic and agricultural conditions at the current time step. These strata pile up in the reservoirs and there is no mixing. Then a piston effect occurs: an inflow at the top of the reservoir leads instantaneously 
to an outflow at the bottom of the reservoir. During this discharge, a strata mixing can occur. Indeed, the concentration of this outflow is calculated with:

$$
\operatorname{Cout}_{i(t)}=\frac{\sum_{i, j=1}^{i, j=n l} C_{i, j} V_{i, j}}{\operatorname{Vout}_{i(t)}}
$$

with Cout $_{i}$ the concentration of the outflow from reservoir $i\left(\mathrm{~kg} \cdot \mathrm{m}^{-3}\right)$, Vout $_{i}$ the volume of the outflow from reservoir $i\left(\mathrm{~kg} \cdot \mathrm{m}^{-3}\right), V_{i, j}$ the volume of the stratum $j$ in the reservoir $i\left(\mathrm{~m}^{3}\right), C_{i, j}$ the concentration of the stratum $j$ in the reservoir $i\left(\mathrm{~kg} \cdot \mathrm{m}^{-3}\right), n l$ the number of drained strata and $t$ the current time step (s).

Water transfer through the UZ is described by equation 3 :

$$
\operatorname{Vin}_{i+1(t)}=\operatorname{Vout}_{i(t)}=\left(\operatorname{Vol}_{i(t)}-V_{\min (i)}\right) \times \delta
$$

with $V_{\min (i)}$ the minimal water volume in the reservoir $i\left(\mathrm{~m}^{3}\right)$.

For numerical reasons, a maximal number of strata is set. When this maximum is reached, an additional mixing occurs: two strata near the $V_{\min }$ are mixed together. In that way, strata mixed due to numerical reasons are located around the top of the reservoir while those mixed during the water transfer are located at the outflow of the reservoir. These mixings lead to diffusion. However, this diffusion is still limited.

NonsatSW has two additional parameters compared to NonsatW. The maximum number of strata $S_{\max }$ is set uniform in the whole domain. The value of the minimal volume $V_{\min }$ can vary in space according to the soil type. As 
initial conditions, the water volume in each reservoir of an UZ is equal to the defined $V_{\min }$. These two parameters do not affect the water transfer dynamics, they impact only the solute transfer. A larger value of $V_{\min }$ generates a longer solute transfer since the solute has to flow through a larger amount of water. The value of the maximum number of strata affects only the diffusion: a small value leads to a larger diffusion of the solute.

\subsection{Improvement of Nonsat}

Gomez et al. (2003) assessed only partially the solute transfer simulated by NonsatSW through the comparison of passive solute velocity with the literature. The more detailed assessment presented in this study, based on comparisons with a physically-based model and in-situ data (cf. section 3), shows some important bias in the solute transfer. In order to improve the quality of the simulations, we propose two modifications: the integration of a saturation profile and a varying percolation rate depending on the water content.

\subsubsection{Introduction of a saturation profile}

The UZ is subject to an evolution of the water content, from its base that is almost saturated to its top that is drier when a steady-state is reached. Van Genuchten (1980) and Brooks and Corey (1966) determined the two main equations describing the water retention curve in an UZ. Figure 3 presents the evolution of the saturation profile as a function of depth in a loamy unsaturated zone as described by Van Genuchten (plain line) for a given set 
of parameters available in Table 2. In NonsatSW the steady-state saturation profile for this type of unsaturated zone is constant in each reservoir and equal to $V_{\min }$ through all the reservoirs (dotted line in Figure 3 ). To improve the realism of the model, a saturation profile is integrated in NonsatSW based on the Van Genuchten (1980) retention curve. This modified version is referred to as NonsatVG. This leads to a variation of the minimal volume $V_{\text {min }}$ between each reservoir as presented in Figure 3 (dashed line) for a loamy soil. For each reservoir, $V_{\min }$ is computed as follows:

$$
V_{\min (i)}=\int_{\text {bottom }_{i}}^{\text {top }_{i}} \frac{1}{\left[1+(\alpha \times \Phi)^{n}\right]^{m}} \times \operatorname{por} \times S \times \Delta z
$$

with $n$ and $\alpha$ the curve parameters, $m=1-\frac{1}{n}$, por the porosity $\left(\mathrm{m} . \mathrm{m}^{-1}\right)$, $S$ the suface of the grid cell $\left(\mathrm{m}^{2}\right)$, and $\Phi$ the capillary pressure head $(\mathrm{m})$. In this study, the discretisation $\Delta z$ used is $10^{-2} \mathrm{~m}$.

As the water volume of the UZ reservoirs increases with the depth, the time transfer of the solute increases too, whereas the velocity transfer is constant in the former version of NonsatSW.

\subsubsection{Evolution of the percolation rate}

The percolation time $\tau$ is related to the time in seconds required to entirely drain a reservoir. A percolation velocity can therefore be approximated from this data. And as $\tau$ is constant in the UZ column, the percolation velocity is considered to be constant. This velocity is not modified by the introduction of a varying saturated profile (equation 4). However, it should vary 
according to the saturation. In order to take this process into consideration, we use in NonsatVG a generalisation of Darcy's law for the saturated zone by assuming that the water transfer is proportional to the saturation. To take this relationship into account, a coefficient of percolation coef is integrated in the model. coef is equal to the saturation fraction of the reservoir:

$$
\begin{gathered}
\text { coef }=\frac{\operatorname{Vol}_{i(t)}}{\operatorname{por} \times S \times d} \\
V i n_{i+1}(t)=\operatorname{Vout}_{i(t)}=\left(\operatorname{Vol}_{i(t)}-V m i n_{i(t)}\right) \times \delta \times \operatorname{coef}
\end{gathered}
$$

with $\mathrm{d}$ the thickness of the reservoir $(\mathrm{m})$.

Indeed, as the saturation fraction increases in the deeper UZ, the outflow of the reservoir increases too.

NonsatVG has therefore 3 additional parameters compared to NonsatSW: the two Van Genuchten's parameters $\alpha$ and $n$ and the porosity. The use of the porosity implies that NonsatVG takes now a maximal volume into account. Indeed, when the volume of water in a reservoir $i$ fills entirely the

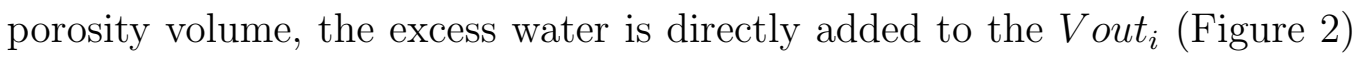
and supplies the reservoir $i+1$.

The need for three additional parameters may be a problem for regional scale modelling. Indeed, $n$ and alpha as well as porosity data are rare for deep UZ which are not easily accessible. Therefore, to specify these three new parameters in regional scale applications, the Carsel and Parrish (1988) database is used. It gives for each soil type the Van Genuchten's parameters 
and the porosity (Table 1). The use of this soil database for the characterisation of the UZ is based on the fact that soils and UZ are defined from the parent material. Different textural soil types individualize therefore different UZ types. An exception is done for the chalk UZ type. This UZ is characterised by a double porosity of matrix and fractures, with a solute transfer occurring mainly in the matrix (Normand et al., 2004; Lacherez-Bastin, 2005). Van Genuchten's parameters defined by Brouyère et al. (2004) for chalk matrix are therefore used for the characterisation of the chalk UZ in our study (Table 1).

\subsection{The physically-based model Metis}

Metis is a mechanistic model comparable to Hydrus-2D (Simunek et al., 1999). Metis is a finite element code solving the water and solute transfer equations in the saturated/unsaturated zones (Goblet, 2007; Larsson, 1992) at each node of a discretized mesh. It describes therefore very precisely the processes occurring in the UZ and, thus, allows a water and solute modelling more realistic than a conceptual model. This model has been applied in various studies: estimation of infiltration velocity in soils (Goblet, 2008), simulations of heat and helium transfer in groundwater (Castro et al., 2005), calculation of groundwater ages (Castro and Goblet, 2005).

Metis uses Van Genuchten's relationships to describe the hydrodynamic prop- 
erties of the UZ. The water retention curve is given by:

$$
S_{e}=\frac{1}{\left[1+(\alpha \Phi)^{n}\right]^{m}}
$$

with $S_{e}$ the effective saturation $\left(\mathrm{m}^{3} \cdot \mathrm{m}^{-3}\right), n$ and $\alpha$ the curve parameters, $m=1-\frac{1}{n}$, and $\Phi$ the capillary pressure head $(\mathrm{m})$.

The hydraulic conductivity curve is described by:

$$
K_{r}=\sqrt{S_{e}}\left[1-\left(1-S_{e}^{\frac{1}{m}}\right)^{m}\right]^{2}
$$

with $K_{r}$ the relative permeability.

$$
S_{e}=\frac{S-S_{r}}{S_{m}-S_{r}}
$$

$S_{e}$ is linked to the saturation of the medium $\mathrm{S}\left(\mathrm{m}^{3} \cdot \mathrm{m}^{-3}\right)$, the maximal saturation $S_{m}\left(\mathrm{~m}^{3} \cdot \mathrm{m}^{-3}\right)$ and the minimal saturation $S_{r}\left(\mathrm{~m}^{3} \cdot \mathrm{m}^{-3}\right) . S_{r}$ is the portion of water in the porosity that can not be displaced by a pressure gradient. $S_{m}$ is the maximal portion of water in the porosity that can be retained by the medium during a saturation. In this study, $S_{m}$ is fixed to 1 and $S_{r}$ to $0 . \mathrm{S}$ is therefore equal to $S_{e}$.

\section{Assessment of NonsatVG}

To assess the new version of the simple UZ scheme, two kinds of comparisons were carried out. First, a comparison with the physically-based model 
Metis was performed in an ideal case, with various UZ depths in two UZ types. Then, two kinds of real cases were studied and the modelling was compared to observed data. In order to assess in NonsatVG the sole impact of the introduction of a saturation profile and a varying percolation rate, the value of the percolation time $\tau$ was the same as in NonsatSW.

\subsection{Ideal case study}

The test consisted in comparing the dynamics of the transfer simulated by Metis, the former and the new version of Nonsat over an UZ column of $20 \mathrm{~m}$ depth with constant infiltration flux and an initial impulse flux of solute. In both Nonsat versions, the thickness of the reservoirs was set to $5 \mathrm{~m}$ (Gomez et al., 2003; Ledoux et al., 2007). In Metis, the column was discretized into 2000 square elements of $10^{-2} \mathrm{~m}$ depth.

NonsatSW, NonsatVG and Metis do not use the same physical variables (saturation in $\%$ for Metis and volume in $\mathrm{m}^{3}$ for Nonsat), neither the same kind of parameters, nor the same spatial geometry. Therefore, in order to compare these models, the following strategy was used:

- As NonsatSW was already applied over the Seine basin, a set of parameters is available for the 7 predominant soil types of the basin (Gomez et al., 2003). Thus, results of NonsatSW were used as a reference. The methodology consisted in calibrating Metis to have similar solute time transfers as NonsatSW at the outflow of the $20 \mathrm{~m}$ column. Default parameters in Metis were provided by using existing databases. Then, 
the calibration was carried out by modifying the saturated hydraulic conductivity and the porosity.

- The Van Genuchten's parameters and the porosity used by NonsatVG were set identical to those of Metis.

- The comparison of the solute time transfer was done at each depth corresponding to the output of each Nonsat reservoir $(5,10,15$ and 20 $\mathrm{m})$.

The test was done with a constant infiltration $\left(1 \mathrm{~mm} \cdot\right.$ day $\left.^{-1}\right)$ and an input of passive contaminant during the first three days. For each UZ type defined by Gomez et al. (2003) in the Seine basin, the parameters required in Metis were determined from Carsel and Parrish (1988) and from Brouyère et al. (2004) databases (Table 1). In order to avoid generating puddles that cannot be managed by Metis, the value of $K_{s}$ was fitted to be compatible with the imposed infiltration.

For the calibration, the first strategy was to have a similar water volume in the soil column, and thus to adjust the porosity in Metis. Then, when the solute transfer simulated by Metis was too fast compared to solute transfer in NonsatSW, $K_{s}$ was decreased or Por was increased. Reverse modifications were performed when solute transfer velocity in Metis was too slow compared to NonsatSW. This calibration process was performed until a good agreement with the solute transfer at the outflow in NonsatSW was reached.

The first test was performed in a loamy UZ column (parameters in Table 
2). Figure 4 presents the time evolution of the solute transfer simulated by NonsatSW, Metis and NonsatVG at the four depths of a loamy UZ. For a given UZ model, the first peak corresponds to the transfer of the solute at 5 $\mathrm{m}$, the second at $10 \mathrm{~m}$, etc. By construction, the average time period needed by the solute to flow through the entire column is comparable in NonsatSW and Metis. When looking at the results at 5, 10, 15 and $20 \mathrm{~m}$ depth, the velocity of the solute transfer in Metis decreases with depth while it is constant in NonsatSW. Also, the mixing increases in Metis, leading to a diminution of the peak and an increase of the duration of the transfer with depth, while NonsatSW presents almost no mixing. NonsatVG leads to a solute transfer which compares better to Metis. The sole introduction of the saturation profile in Nonsat ('NonsatVG-Darcy' in Figure 4) leads to a decrease of the solute transfer velocity with depth and an increase of the mixing. However, the mixing is not as large as in Metis and the solute reaches the $20 \mathrm{~m}$ depth $10 \%$ earlier than in Metis. By using the same $\tau$ in NonsatVG as in NonsatSW, but considering in addition an evolutive percolation coefficient in the column, the results obtained in NonsatVG are more similar to those of Metis.

To assess the robustness of the model, different depths of the UZ were tested. As the saturation profile varies according to the water table depth, the variation of the UZ depth should impact the solute transfer. The tests were done by assuming the same parameters as those calibrated for a $20 \mathrm{~m}$ deep UZ. The results are presented in Figure 5 and Table 3 for a loam UZ type. 
Compared to NonsatSW, the time required by the solute in NonsatVG to reach a $5 \mathrm{~m}$ depth is longer for a shallower UZ. This is consistent with Metis simulation. This is due to the fact that there is more water contained in the first $5 \mathrm{~m}$ of the UZ when the water table is closer to the surface. Thus, the solute has to flow through a greater volume of water to go beyond the first 5 $m$ and the transfer velocity decreases. Such dynamics are not represented by NonsatSW which has a constant velocity, but is well captured by NonsatVG. The same kind of tests was also performed on a chalk column. The results presented in Table 3 lead to the same conclusion: the modifications introduced in NonsatVG lead to results comparable to those of the physical model Metis, with a decrease of the solute transfer at a given depth when the water table is shallower. However, for this UZ case, variations of solute transfer velocity are low. Indeed, the Van Genuchten's parameters used for a chalky UZ generate a saturation greater than $90 \%$ through the column. The variations of the saturation profile with a piezometric level are therefore small.

Calibrated parameters obtained with this methodology for these comparison tests differ significantly from the Carsel and Parrish (1988) and Brouyère et al. (2004) databases. After calibration, the defined $K_{s}$ for loam is three orders of magnitude larger than the one from Carsel and Parrish (1988) (respectively $8.15 .10^{-3} \mathrm{~m} . \mathrm{s}^{-1}$ and $2.89 .10^{-6} \mathrm{~m} \cdot \mathrm{s}^{-1}$ ). For chalk, the porosity is decreased to an unrealistic value (por $\left.=8.50 .10^{-2} \mathrm{~m} \cdot \mathrm{m}^{-1}\right)$ when compared to the in situ observed water content (Normand et al., 2004; Amraoui et al., 2008). Such parameters are unrealistic, which probably means that the so- 
lute transfer simulated by NonsatSW with the parameters defined over the Seine basin is biased. The following section confirms this assumption by using in-situ data.

\subsection{Assessment of NonsatVG with observed data}

In order to assess more accurately the new model, water and solute transfer dynamics obtained with NonsatVG were compared with in situ data. Two kinds of data were used: some piezometric levels in the Seine basin and the monitorings of the nitrate concentration profile in two sites in Northern France located in the Seine basin.

\subsubsection{Comparison with the observed piezometric head}

The sole introduction of a saturation profile in NonsatVG does not modify the water table fluctuation simulated by MODCOU with NonsatSW (equation 3). However, the introduction of a relation between the percolation ratio and the saturation ratio modifies the dynamics of the flow. The general trend is a lower water transfer velocity through the UZ (equation 6) that generates a modification of the dynamics of the simulated piezometric levels.

In order to evaluate the impact of such a modification on the water transfer, a comparison of the observed and the simulated piezometric head was performed over the Seine basin. The simulations were performed using the same model MODCOU (Ledoux et al., 2007) to estimate the surface water budget, and thus the infiltration in the UZ, and the water transfer in the aquifer. Thus, the differences in the simulation of the piezometric head were only due 
to the differences in the simulation of the water table recharge. Figure 6 shows the comparison of the evolution of the piezometric level observed and simulated by MODCOU with NonsatSW and NonsatVG at the Mainvilliers well (48 27' 12" North, 1 ${ }^{\circ} 27^{\prime}$ 43" East) between 1981 and 2004. It can be noticed that the fluctuations of the piezometric head are dampened in NonsatVG compared to NonsatSW. However, it is not clear if this dampening leads to an improvement or a degradation of the simulation of the observed piezometric head. Similar results are obtained in the other piezometric wells of the Seine basin. Figure 7 presents the statistical criteria (bias and root mean square error) obtained by NonsatSW and NonsatVG for 32 wells. It appears that the two statistical results are very similar for both models. This result means that this modification does not make NonsatVG more or less valid than NonsatSW for the simulation of piezometric fluctuations.

\subsubsection{Local comparison of the solute transfer}

The Agro-Impact group from INRA (Institut National de Recherche Agronomique - National Institute in Agronomical Research) at Laon (North France) monitors nitrate transfer through two chalky UZ at Haussimont (48 $45^{\prime} 0^{\prime \prime}$ North - 4 ${ }^{\circ} 10^{\prime} 0 "$ East) and Thibie (48 55' 49" North - 4 ${ }^{\circ} 12^{\prime}$ 59” East) in the Champagne-Ardenne Region (Normand et al., 2004).

At Haussimont, nitrate concentration profiles from 1 to $20 \mathrm{~m}$ deep are available from 1982 to 2004. At Thibie, nitrate concentration profiles from 0.13 to $6 \mathrm{~m}$ deep were monitored from 1990 to 2008. For both sites, the propaga- 
tion of a nitrate peak through time can be observed. This type of long-term experiment is not very common and provides very useful data to both understand the transfer of nitrate through the UZ and assess its modelling. We used therefore this data set to test the three UZ schemes.

All required data to perform a simulation of the experimental sites are not available. For instance, the time evolution of the infiltrations and their nitrate concentrations are unknown. Therefore, to simulate these real cases, some approximations were done. The first nitrate concentration profile (1982 for Haussimont and 1990 for Thibie) was imposed as an initial condition and no additional nitrate input was assumed. And while the site experienced annual rotations of winter wheat, sugar beet, lucerne and winter barley, we considered only a generic crop type. Thus, it did not take the real land use into account. The water percolation flux was subsequently determined with the water balance module of the MODCOU model (Ledoux et al., 2007) that was already applied over the Seine basin. Daily precipitation and potential evaporation data for both sites were provided by the SAFRAN analysis of Météo-France (Quintana Seguì et al., 2008). A constant depth of the water table was assumed and was set equal to a $25 \mathrm{~m}$ depth at Haussimont and a $15 \mathrm{~m}$ depth at Thibie according to neighbouring piezometric wells. An initial profile along the nodes in Metis and the strata in NonsatSW and NonsatVG was extrapolated from the observed data (triangular lines in Figures 8 and $9)$.

Three simulations were performed: the first one was done with NonsatSW 
with the parameter calibrated by Gomez et al. (2003) for a chalk UZ. The two other ones were done with Metis and NonsatVG. Required parameters values for the three models are presented in Table 4. As these simulation tests had to be performed in the most similar conditions to those prevailing on the experimental sites, the defined parameters for each models had to be realistic. So, contrary to tests in the ideal case, no additonal calibration was considered. Indeed,Van Genuchten's parameters and porosity in Metis and NonsatVG were determined from Brouyère et al. (2004). In order to avoid generating puddles in the physically-based model, the $K_{s}$ in Metis was set to $9.00^{-7} \mathrm{~m} . \mathrm{s}^{-1}$. In NonsatVG, the value of $\tau$ defined by Gomez et al. (2003) was used. In Metis, the dispersivity was set according to the simulation of the LIXIM model (dispersivity=1.25.10 ${ }^{-1} \mathrm{~m}$, Mary et al. (1999)).

Haussimont site. From 1982 to 1999, total amount of nitrate in the UZ at Haussimont increases due to successive supplies from agricultural activities. Then from March 2001, a significant decrease of the total amount of nitrate in the $\mathrm{UZ}$ is observed. At the same time, the nitrate peak is not in evidence anymore (triangular lines in Figures 8). We considered therefore that the main peak was transferred through the UZ. Thus, the comparison between observed and simulated profiles only focused on the evolution of the nitrate peak observed in 1982 through 18 years. The nitrate peak is $5 \mathrm{~m}$ deep in May 1982, $7 \mathrm{~m}$ deep in March 1986, and $14 \mathrm{~m}$ deep in March 2000. The average transfer velocity (ATV) of this peak in this UZ is therefore $0.50 \mathrm{~m}_{\text {.year }}{ }^{-1}$ which is comparable to results of other studies (Serhal et al., 2006). 
The results of the comparison are presented in Figure 8. Metis simulates an evolution of the concentration profiles that is close to the observed one. The depth of the peak for each given date and the diffusion are however slightly underestimated $\left(\mathrm{AVT}=0.40\right.$ m.year $\left.{ }^{-1}\right)$. NonsatSW is not able to reproduce the observed profiles: the modelised solute peak is transferred too quickly (almost $10 \mathrm{~m}$ in only 4 years, AVT=2.50 m.year ${ }^{-1}$ ). Compared to NonsatSW, the profiles simulated by NonsatVG are improved, with a longer solute time transfer. However, the transfer velocity is too slow, since the peak reaches in 18 years only $13 \mathrm{~m}$ instead of the observed $14 \mathrm{~m}\left(\mathrm{AVT}=0.44 \mathrm{~m} . \mathrm{year}^{-1}\right)$. During all simulations, the peak simulated by Metis is shallower than the observed one. It is not the case in NonsatVG. In April 1991, the solute peak simulated by NonsatVG has an average depth close to the observations. But from March 1997, the peak simulated by NonsatVG remains shallower than the observed one. Then it seems that the solute transfer simulated in NonsatVG is faster at the top of the UZ and slows down to the aquifer. These dynamics could be seen also in the ideal case (Figure 4). It can be also noticed that the dispersion simulated by NonsatVG does not compare well to the observed one. At Haussimont, the peak intensity decreases by $30 \%$ in 18 years. In Metis, this peak decreases by more than $20 \%$ whereas in NonsatVG, the peak is almost identical at the beginning and at the end of the simulation.

Thibie site. The main peak observed in the first available profile in October 1990 is almost totally transferred through the UZ in October 2008. Thus, the 
comparison between observed and simulated profiles focused on the evolution of the nitrate peak from 1990 to 2003 . The nitrate peak is $1.65 \mathrm{~m}$ deep in October 1990, $1.88 \mathrm{~m}$ in October 1993, $4.13 \mathrm{~m}$ in October 1999 and $5.88 \mathrm{~m}$ in October 2003. The ATV of this peak is therefore 0.32 m.year ${ }^{-1}$. The results of the comparison are presented in Figure 9. Contrary to Haussimont, the depths of the peaks are overestimated in NonsatVG and Metis. The AVT is respectively $0.38 \mathrm{~m} . \mathrm{year}^{-1}$ and $0.47 \mathrm{~m} . \mathrm{year}^{-1}$ for the new version of Nonsat and the physically-based model. The closest simulated evolution of the concentration profiles is therefore performed by NonsatVG. However, it simulates almost no dispersivity. In Metis, the nitrate peak intensity decreases by $35 \%$ through the simulated period which is in good agreement with the observed peak (decrease of $40 \%$ ).

None of the three models is able to accurately reproduce the observed profiles. A part of this inaccuracy is due to the physics of the models. But it can also be due to errors on the estimation of the infiltration or on the estimation of the parameters. It is assumed that with an improved physics, realistic parameters as those derived from available databases should lead to realistic results. Thus, several additional tests were performed by varying the infiltration and the parameters.

A first set of tests was done with an annual average infiltration value set according to the simulation of the LIXIM model (Mary et al., 1999). The infiltration flux is $25 \%$ larger for Haussimont and $33 \%$ lower for Thibie. Instead of using parameters defined for the chalk, we used Van Genuchten's 
parameters from the Carsel and Parrish (1988) database for the closest soil type, ie, clay (Table 1) in a second set of tests. For NonsatSW, several tests were done by increasing the minimal water volume $V_{\min }$ to get closer to realistic values, or by increasing the percolation time $\tau$ (which is equivalent to decrease the hydraulic conductivity).

For each test, an error was computed as follow:

$$
R M S E=\sqrt{\frac{1}{n} \sum_{i=1}^{n}\left(\text { Dpeak }_{i}^{\text {obs }}-\text { Dpeak }_{i}^{\text {simu }}\right)^{2}}
$$

with $n$ the number of compared profiles, and Dpeak $k_{i}^{o b s}$ and Dpeak $k_{i}^{s i m u}$ the depth of respectively the observed and the simulated nitrate peaks at the profile $i$. Figure 10 presents the mean values of this RMSE for the three models at Haussimont. For each model, a set of parameters allows to obtain good results (RMSE close to zero). Metis obtains almost similar RMSE with chalk and clay parameters. RMSE is however better with the LIXIM infiltration $(\mathrm{RMSE}=0.40)$ than with the infiltration from MODCOU $(\mathrm{RMSE}=0.90)$. Similar results are also observable at Thibie site for Metis. The parameters from NonsatSW have to be adjusted for both sites $\left(V_{\min }\right.$ multiplied by a factor of 5). With the default parameters, the RMSE was large (around $10 \mathrm{~m})$. As the parameters from NonsatSW do not rely on classical physical parameters, they could not be set according to the available databases. With NonsatVG, chalk parameters allow to obtain better RMSE than clay parameters (RMSE around $1 \mathrm{~m}$ and $4 \mathrm{~m}$ respectively) for both sites. The 
most reduced RMSE in NonsatVG are obtained with the infiltration from MODCOU at Haussimont. On the contrary at Thibie, the solute transfer is improved with the LIXIM infiltration.

From these results, it is clear that without any additional calibration, the new version of Nonsat is in better agreement than the former version with the physically-based model and the observed data. A good agreement between the former version of Nonsat and the observed data is obtained only after an appropriate calibration of the $V_{\min }$. We also demonstrate that application of NonsatVG is simple as the use of existing databases is conclusive. Furthermore, NonsatVG model is still more time efficient than the physically-based model.

\section{Impact on the estimation of the solute transfer time in the Seine basin}

The comparisons with local observations show that NonsatVG seems to simulate the solute transfer better than NonsatSW. It is interesting to see how these differences have an impact on the nitrate transfer to the aquifers of the Seine basin. Therefore, a 35-year simulation was done, with a passive solute input imposed at the beginning of the simulation, and the real atmospheric forcing imposed from 1971 to 2006 . The estimation of the infiltration in the UZ was computed by MODCOU (Ledoux et al. 2007). The Seine basin is characterised by a weak infiltration in the center of the basin (less than 100 mm.year ${ }^{-1}$ ) where the aquifers lie (Figure 11). 
Figure 12 presents the nitrate transfer velocity for the cells located on chalky, clay and sandy soil types as a function of the accumulated annual infiltration simulated both by NonsatVG and NonsatSW. As expected, the velocity increases with the accumulated infiltration and can vary by a factor of 3 . On average, it seems that the solute velocity for chalk, sand and clay is around 2 m.year ${ }^{-1}$ for NonsatSW. In NonsatVG, the solute velocity is around 1 m.year ${ }^{-1}$ in chalky and clay UZ and around 3 m.year ${ }^{-1}$ in sand. The solute time transfer in a sandy column with NonsatVG seems to be more scattered than in the chalk for a given average infiltration rate. This is due to the fact that the water volume in a sandy UZ varies according to the unsaturated depth. In chalk, such a variation is attenuated because the column is almost saturated along the whole column. The velocity value obtained with NonsatVG in the chalky UZ is closer than NonsatSW to the observed data for similar soil types: 0.80 to 0.90 m.year ${ }^{-1}$ (Jackson et al., 2006) and 0.60 to 1.25 m.year ${ }^{-1}$ (Serhal et al., 2006). It is also the case for the clay UZ type with 0.27 to 0.42 m.year ${ }^{-1}$ (Johnson et al., 1989). Concerning the sandy UZ, the solute transfer velocity obtained with NonsatVG seems also in better agreement than NonsatSW with the literature $\left(2\right.$ m.year ${ }^{-1}$, Legout et al. (2007)).

Figure 13 shows the distribution of the nitrate time transfer in the basin as simulated by NonsatSW and NonsatVG. There is a shift between the two simulations: in NonsatVG, a significant part of the UZ in the Seine basin transfers the pollutant in about 10-15 years while in NonsatSW, the most 
important transfer of pollutant to the saturated zone occurs before 10 years of simulation. In NonsatVG, 17 years are required for a solute to reach the water table on $50 \%$ of the basin, while it is only 12 years with NonsatSW. Figure 14 presents the map of the nitrate time transfer in the Seine basin. It easily reaches 30 years and even more than 50 years where the aquifer is deep. This solute time transfer seems to be longer than the one obtained by Sohier et al. (2009) in a chalk basin in Belgium, where most of the solute reached the water table in 15 years. This might be due to a thicker unsaturated zone in the Seine basin.

\section{Conclusion}

An improvement of a simple scheme that simulates the transfers of solute and water in the unsaturated zone using a cascade of reservoirs is proposed. Two modifications are made: a) introduction of a saturation profile with depth, according to the Van Genuchten's equations and b) evolution of the drainage velocity of the reservoirs according to their saturation.

In order to assess such modifications, comparisons with the physically-based model Metis are presented in both ideal and real cases. These comparisons show that the original version of the simple model NonsatSW is not able to represent properly the evolution of the solute transfer for different water table depths. The new version, NonsatVG, can better reproduce these dynamics. Indeed, results obtained with this new version compare fairly well with results of Metis. But the definite advantage of NonsatVG compared 
to Metis is that the relevant code is more computationally efficient. This aspect makes NonsatVG easily applicable at regional scale as needed when modelling a full hydrological basin.

One critical aspect is the determination of three additional parameters. To define them at regional scale, we use the Carsel and Parrish (1988) database that links these parameters to 12 FAO soil types. An exception is made for the chalky UZ type. Indeed, this medium is characterised by a double porosity of matrix and fractures with a dominant matricial water transfer (Brouyère et al., 2004; Normand et al., 2004). The matrix is almost saturated and generates a water transfer through the UZ by a piston effect (Headworth, 1972). To take into account these particular unsaturated dynamics, Van Genuchten's parameters defined by Brouyère et al. (2004) for the UZ chalk matrix are therefore used. The sensitivity tests presented in this study show the relevance of using such parameters for this type of UZ. As tests related to ideal and real cases demonstrate that NonsatVG obtains a better solute transfer through the UZ than NonsatSW, a comparison test was performed on the whole Seine basin from 1971 to 2006. Results show that, without significant modifications of the water table fluctuations, NonsatVG modifies significantly nitrate transfer dynamics at the Seine basin scale. The solute transfer through the UZ is globally slower with NonsatVG than with NonsatSW and in better agreement with literature and in-situ data.

Brouyère et al. (2004) and Legout et al. (2007) showed that the fluctuations of the piezometric level also modify greatly the contamination dynamics in 
the groundwater. Indeed, when it rises, the solute in the UZ is washed and when it drops, the contamination from the UZ to the saturated zone decreases. In order to improve the dynamics of the solute transfer at the interface unsaturated-saturated zones, the fluctuations of the water table should therefore be taken into account. The modifications provided in NonsatVG give a direct link between the water table depth and the saturation profile in the UZ. We can therefore take into account explicitly the water table fluctuations in the UZ. Details are presented by Philippe et al. (2009) and the work is underway to simulate this phenomenon on the Seine basin. As it will have a direct impact on the groundwater nitrate concentration modelling, we expect to improve the simulation quality of STICS-MODCOU in the Seine basin by reducing the large local errors that exist in the simulation of the groundwater contamination (Ledoux et al., 2007).

\section{Acknowledgments}

This project is included in the programme INSU EC2CO Eau'dyssée. The authors would like to thank R2DS Ile-de-France for the funding of this research project and the PIREN-Seine research programme. They would also like to thank Mr Jean-Pol Prévost and Mr Pascal Foy who have collected the long-term data in Haussimont and Thibie sites.

Amraoui N, Machard de Gramont H, Robelin C, Wuilleumier A, Noyer ML,

Feret MJ. 2008. Flow processes in the unsaturated Chalk of the Hallue 
Basin (France). In Unsaturated Soils: Advances in Geo-Engineering, Toll et al. (eds).

Baran N, Richert J, Mouvet C. 2007. Field data and modelling of water and nitrate movement through deep unsaturated loess. Journal of Hydrology 345: $27-37$.

Besbès M, De Marsily G. 1984. From infiltration to recharge: use of parametric transfer function. Journal of Hydrology 74: 271-293.

Birkinshaw SJ, Ewen J. 2000. Nitrogen transformation component for SHETRAN catchment nitrate transport modelling, Journal of Hydrology 230: $1-17$.

Brisson, N, Mary B, Ripoche D, Jeuffroy MH, Ruget F, Nicoullaud B, Gate P, Devienne-Barret F, Antonioletti R, Durr C, Richard G, Beaudoin N, Recous S, Tayot X, Plenet D, Cellier P, Machet JM, Meynard JM, Delecolle R. 1998. STICS: a generic model for the simulation of crops and their water and nitrogen balances. I. Theory and parameterization applied to wheat and corn. Agronomie 18: 311-346.

Brooks RH, Corey AT. 1966. Properties of porous media affecting fluid flow. Journal of the Irrigation and Drainage Division, Proceedings of the American Society of Civil Engineers 92: 61-88.

Brouyère S, Dassargues A, Hallet V. 2004. Migration of contaminants 
through the unsaturated zone overlying the Hesbaye chalky aquifer in Belgium: a field investigation. Journal of Contaminant Hydrology 72, 135-164.

Carsel RF, Parrish RS. 1988. Developing Joint Probability Distributions of Soil Water Retention Characteristics. Water Resources Research 24: 755769.

Castro MC, Goblet P. 2005. Calculation of Ground Water Ages - A comparative Analysis. Ground Water 43: 368-380.

Castro MC, Patriarche D, Goblet P. 2005. 2-D numerical simulations of groundwater flow, heat transfer and He transport - implications for the He terrestrial budget and the mantle helium-heat imbalance. Earth and Planetary Science Letters 237: 893-910.

Flipo N, Even S, Poulin M, Théry S, Ledoux E. 2007. Modeling nitrate fluxes at the catchment scale using the integrated tool CAWAQS Science of the Total Environment 375: 69-79.

Goblet P. 2007. Spécifications pour la simulation de l'écoulement en zone non saturée. Rapport final. IRSN/DSU/SSIAD.

Goblet P. 2008. Estimation des vitesses de filtration de l'eau dans les sols de CNPE - Identification de régime-types d'écoulement. Rapport technique No R080318PGOB, Centre de Geosciences, Ecole des Mines de Paris, Fontainebleau, France. 
Gomez E, Ledoux E, Viennot P, Mignolet C, Benoit M, Bornerand C, Schott C, Mary B, Billen G, Ducharne A, Brunstein D. 2003. Un outil de modélisation intégrée du transfert des nitrates sur un système hydrologique: application au bassin de la Seine. La Houille Blanche $\mathbf{3}$.

Gutierrez A, Baran N. 2009. Long-term transfer of diffuse pollution at catchment scale: Respective roles of soil, and the unsaturated and saturated zones (Brévilles, France). Journal of Hydrology 369: 381-391.

Headworth HG, BSC, DIC, FGS (Professional Associate), Hydrologist Hampshire River Authority 1972. The analysis of natural groundwater level fluctuations in the chalk of Hampshire. Journal of the Institute of Water Engineering 26: 107-124.

Jackson BM, Wheater H, Mathias SA, McIntyre N, Butler AP. 2006. A simple model of variable residence time flow and nutrient transport in the chalk. Journal of Hydrology 330: 221-234.

Johnson RL, Cherry JA, Pankow JF. 1989. Diffusive Contaminant Transport in Natural Clay: A Field Example and Implications for Clay-Lined Waste Disposal Sites. Environmental Science \&6 Technology 23: 340-349.

Lacherez-Bastin S. 2005. Contribution á l'étude de la migration des nitrates dans le sol et la zone non saturée de la nappe de la Craie dans le Nord de la France. Thèse de Doctorat, Ecole Polytechnique Universitaire de Lille. 
Larsson A. 1992. The international projects INTRACOIN, HYDROCOIN and INTRAVAL. Advances in Water Resources 15: n ${ }^{\circ} 1$ (8 ref.) 85-87

Ledoux E, Gomez E, Monget JM, Viavattene C, Viennot P, Benoit M, Mignolet C, Schott C, Mary B. 2007. Agriculture and Groundwater Nitrate Contamination in the Seine Basin. The STICS-MODCOU modelling chain. Science of the Total Environment 375: 33-47.

Legout C, Molenat J, Aquilina L, Gascuel-Odoux C, Faucheux M, Fauvel Y, Bariac T. 2007. Solute transfer in the unsaturated zone-groundwater continuum of a headwater catchment. Journal of Hydrology 332: 427-441.

Mary B, Beaudoin N, Justes E, Machet JM. 1999. Calculation of nitrogen mineralization and leaching in fallow soil using a simple dynamic model. European Journal of Soil Science 50: 549-566.

Mignolet C, Schott C, Benoît M. 2007. Spatial dynamics of farming practices in the Seine basin: Methods for agronomic approaches on a regional scale. Science for the Total Environment 375: 13-32.

Nash JE, ME, AMICEI. 1960. A unit hydrograph study, with particular reference to british catchments.

Neitsch SL, Arnold JG, Kiniry JR, Williams JR. 2005. Soil and Water Assessment Tool Theoretical Documentation.

Normand B, Mary B, Czernichowski I, Beaudoin N, Mouvet C, Bazerque MF, Groell F. 2004. Programme expérimental de suivi de la qualité de 
l'eau sur trois bassins versants de Picardie faisant l'objet de mesures agrienvironnementales. Rapport de synthèse.

O'Shea L, Wade A. 2009. Controlling nitrate pollution: an integrated approach. Land Use Policy 26: 199-808.

Philippe E, Habets F, Ledoux E, Goblet P, Viennot P. 2009. Improvement of nitrate transfer modelling in a drainage basin: consideration of water table fluctuations in the unsaturated zone. Proceedings of the $16^{\text {th }}$ Nitrogen Workshop, Turin.

Quintana Segui P, Le Moigne P, Durand Y, Martin E, Habets F, Baillon M, Canellas C, Franchisteguy L, Morel S. 2008. Analysis of Near Surface Atmospheric Variables: validation of the SAFRAN analysis over France. Journal of Applied Meteorology and Climatology 47: 92-107.

Refsgaard JC, Storim B. 1995. MIKE SHE. Computer Models of Watershed Hydrology. Water Resources Publication, 809-846.

Refsgaard JC. 2002. Harmonising Quality Assurance in model based catchment and river basin management. State-of-the-Art Report on Quality Assurance in modelling related to river basin management. Contract EVK2CT2001-00097. HarmoniQua project.

Rivett OM, Buss SR, Morgan P, Smith JWN, Bemment CD. 2008. Nitrate attenuation in groundwater: a review of biogeochemical controlling processes. Water Research 42: 4215-4232. 
Serhal H, Bastin-Lacherez S, Bernard D, El Khattabi J. 2006. Etude de la migration des nitrates dans la nappe à travers la zone non saturée: enjeux et impact sur la qualité de l'eau exploitée. Darcy 67. Colloque international - Gestion des grands aquifères - 30 mai-1er juin 2006. Dijon, France.

Simunek J, Sejna M., Van Genuchten M.Th. 1999. The Hydrus-2D software package for simulating two-dimensional movement of water, heat, and multiple solutes in variably saturated media. Version 2.0. IGWMC-TPS-53, International Ground Water Modeling Center, Colorado School of Mines, Golden, Colorado, 251pp.

Sohier C, Degré A, Dautrebande S. 2009. From root zone modelling to regional forecasting of nitrate concentration in recharge flows - The case of the Walloon Region (Belgium). Journal of Hydrology 369: 350-359.

Van Genuchten MTh. 1980. A Closed-form Equation for Predicting the Hydraulic Conductivity of Unsaturated Soils. Soil Science Society of American Journal 44: 892-898.

Vauclin M. 1993. Modélisation du transport de solutés dans la zone non saturée du sol. Revue des Sciences de l'Eau 7: 81-102.

Viennot P, Ledoux E, Monget JM, Schott C. 2006. Contamination nitrique des aquifères du bassin de la Seine. Document de synthèse PIREN Seine 2006. 
Table 1: Average values for selected soil water retention and hydraulic conductivity parameters for 12 major soil textural groups according to Carsel and Parrish (1988), and for chalk matrix according to Brouyère et al. (2004). $\theta_{r}$ and $\theta_{s}$ are the minimal and the maximal saturation of the medium $\left(\mathrm{m} \cdot \mathrm{m}^{-1}\right), \alpha\left(\mathrm{m}^{-1}\right)$ and $n(-)$ are the Van Genuchten's parameters and $K_{s}$ is the saturation permeability $\left(\mathrm{m} . \mathrm{s}^{-1}\right)$. In the last column, the corresponding soil type defined by Gomez et al. (2003) on the Seine basin.

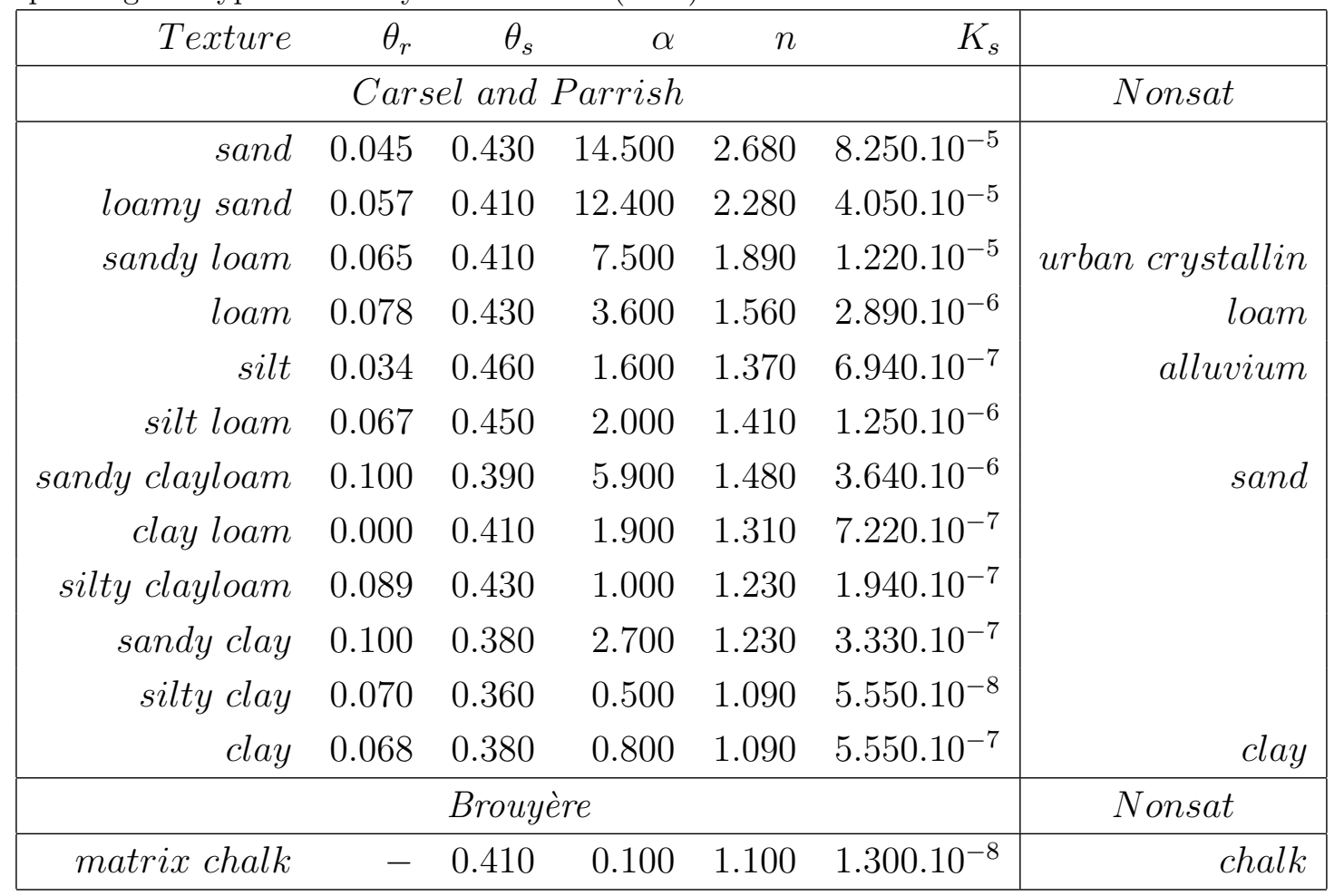


Table 2: Set of parameters used in NonsatSW, NonsatVG and Metis for the ideal case. $\mathrm{N}$ is the number of reservoirs, thick is the thickness of the unsaturated zone $(\mathrm{m})$ that is to say the product $N \times d$ with $d$ the reservoir's thickness ( $5 \mathrm{~m}$ in this study), $n q u$ is the number of nodes, $V_{\text {min }}$ is the minimal water volume in each reservoir $\left(\mathrm{m}^{-\mathrm{m}^{-1}}\right)$, por is the porosity $\left(\mathrm{m} . \mathrm{m}^{-1}\right), n$ and $\alpha$ are the Van Genuchten's parameters, disper sivity is the solute dispersion $\left(10^{-2} \mathrm{~m}\right)$ and $K_{s}$ is the saturation permeability $\left(\mathrm{m} . \mathrm{s}^{-1}\right) . K_{s}$ in NonsatSW and NonsatVG is determined from the percolation time $\tau(\mathrm{s})$ and the reservoir's thickness $d$ by considering a unit gradient: $K_{s}=\frac{d}{\tau}$.

\begin{tabular}{rrr|rrr}
\hline \multicolumn{1}{c}{ Loam UZ } & \multicolumn{3}{c}{ Chalky UZ } \\
\hline NonsatSW & NonsatVG & \multicolumn{1}{c}{ Metis } & NonsatSW & NonsatVG & \multicolumn{1}{c}{ Metis } \\
\hline$N=4$ & $N=4$ & $n q u=2000$ & $N=4$ & $N=4$ & nqu $=2000$ \\
$K_{s}=1.15 .10^{-5}$ & $K_{s}=1.15 .10^{-5}$ & $K_{s}=8.15 .10^{-3}$ & $K_{s}=1.15 .10^{-5}$ & $K_{s}=1.15 .10^{-5}$ & $K_{s}=9.00 .10^{-7}$ \\
thick $=20$ & thick $=20$ & thick $=20$ & thick $=20$ & thick $=20$ & thick $=20$ \\
$V_{\text {min }}=0.07$ & por $=0.33$ & por $=0.33$ & $V_{\text {min }}=0.08$ & por $=8.50 .10^{-2}$ & por $=8.50 .10^{-2}$ \\
& $n=1.56$ & $n=1.56$ & & $n=1.10$ & $n=1.10$ \\
& $\alpha=3.60$ & $\alpha=3.60$ & & $\alpha=0.10$ & $\alpha=0.10$ \\
& & & & dispersivity $=1$ \\
\hline
\end{tabular}

Table 3: Average passive solute velocity transfer $\left(m . y e a r^{-1}\right)$ obtained with NonsatSW, NonsatVG and Metis to reach a given depth D (m) considering a given water table depth WT $(\mathrm{m})$ for the ideal case.

\begin{tabular}{|c|c|c|c|c|c|c|c|}
\hline & & \multicolumn{3}{|c|}{ Loam UZ } & \multicolumn{3}{|c|}{ Chalk UZ } \\
\hline$W T$ & $D$ & Nonsat $_{S W}$ & Nonsat $_{V G}$ & Metis & Nonsat $_{S W}$ & Nonsat $_{V G}$ & Metis \\
\hline \multirow{4}{*}{20} & 5 & 8.70 & 11.40 & 13.00 & 7.60 & 7.90 & 7.90 \\
\hline & 10 & 8.70 & 11.40 & 12.20 & 7.60 & 7.80 & 7.90 \\
\hline & 15 & 8.70 & 11.06 & 11.40 & 7.60 & 7.70 & 7.90 \\
\hline & 20 & 8.70 & 8.80 & 8.80 & 7.60 & 7.70 & 7.80 \\
\hline \multirow{3}{*}{15} & 5 & 8.70 & 11.40 & 14.80 & 7.60 & 7.80 & 7.90 \\
\hline & 10 & 8.70 & 10.90 & 13.00 & 7.60 & 7.70 & 7.80 \\
\hline & 15 & 8.70 & 8.10 & 8.70 & 7.60 & 7.60 & 7.60 \\
\hline \multirow{2}{*}{10} & 5 & 8.70 & 11.10 & 11.40 & 7.60 & 7.60 & 7.70 \\
\hline & 10 & 8.70 & 7.00 & 7.20 & 7.60 & 6.50 & 7.60 \\
\hline
\end{tabular}


Table 4: Set of parameters used in NonsatSW, NonsatVG and Metis for comparison with observed data. $\mathrm{N}$ is the number of reservoirs, thick is the thickness of the unsaturated zone (m) that is to say the product $N \times d$ with $d$ the reservoir's thickness $(5 \mathrm{~m}$ in this study), nqu is the number of nodes, $\tau$ is the percolation time $\left(\mathrm{m} . \mathrm{s}^{-1}\right), V_{\min }$ is the minimal water volume in each reservoir $\left(\mathrm{m} \cdot \mathrm{m}^{-1}\right)$, por is the porosity $\left(\mathrm{m} \cdot \mathrm{m}^{-1}\right), n$ and $\alpha$ are Van Genuchten's parameters, dispersivity is the solute dispersion $\left(10^{-2} \mathrm{~m}\right)$ and $K_{s}$ is the saturation permeability $\left(\mathrm{m} . \mathrm{s}^{-1}\right) . K_{s}$ in NonsatSW and NonsatVG is determined from the percolation time $\tau$ (s) and the reservoir's thickness $d$ by considering a unit gradient: $K_{s}=\frac{d}{\tau}$.

\begin{tabular}{r|r|r}
\hline NonsatSW & NonsatVG & \multicolumn{1}{c}{ Metis } \\
\hline$N=5$ & $N=5$ & nqu $=5000$ \\
thick $=25$ & thick $=25$ & thick $=25$ \\
$K_{s}=1.15 .10^{-5}$ & $K_{s}=1.15 .10^{-5}$ & $K_{s}=9.00 .10^{-7}$ \\
$V_{\text {min }}=0.08$ & por $=0.41$ & por $=0.41$ \\
& $n=1.10$ & $n=1.10$ \\
& $\alpha=0.10$ & $\alpha=0.10$ \\
& & dispersivity $=12.50$ \\
\hline
\end{tabular}




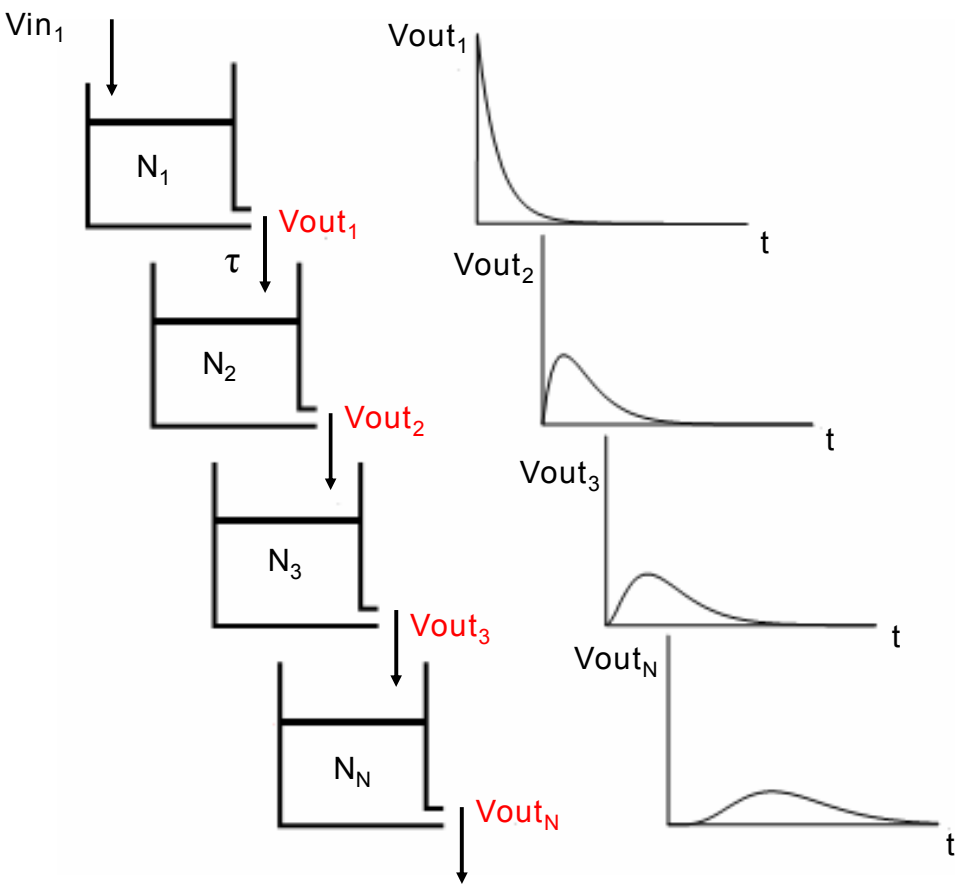

Figure 1: Representation of the Nash cascade, with $N$ the reservoir and $\tau$ the percolation time (s). $N$ varies from $\mathrm{N}_{1}$ to $\mathrm{N}_{N}$. Vin $n_{1}$ is the infiltration at the surface of the UZ, Vout ${ }_{i}$, $i$ varying from 1 to $N$, is the outflow from each reservoir $N_{i}$. The amplitude of the given infiltration is modified by the transfer through the cascade. 


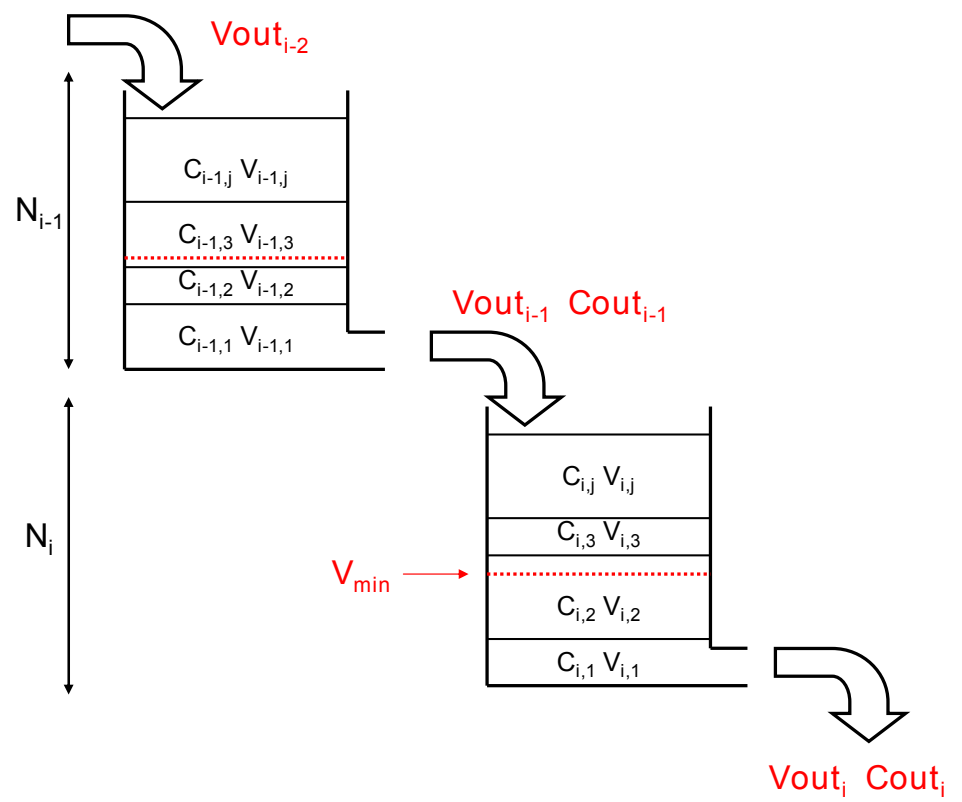

Figure 2: Representation of the passive solute transfer through the UZ in NonsatSW with 2 reservoirs N. $V_{\text {min }}$ is the minimal water volume in each reservoir and $C_{i, j}$ and $V_{i, j}$ the concentration and the volume of each stratum $j$ in each reservoir $i$. An infiltration at the surface of the unsaturated zone at the time step $t$ generates an immediate water outflow with a volume Vout $_{i}$ and a concentration Cout $_{i}$ by piston effect. 


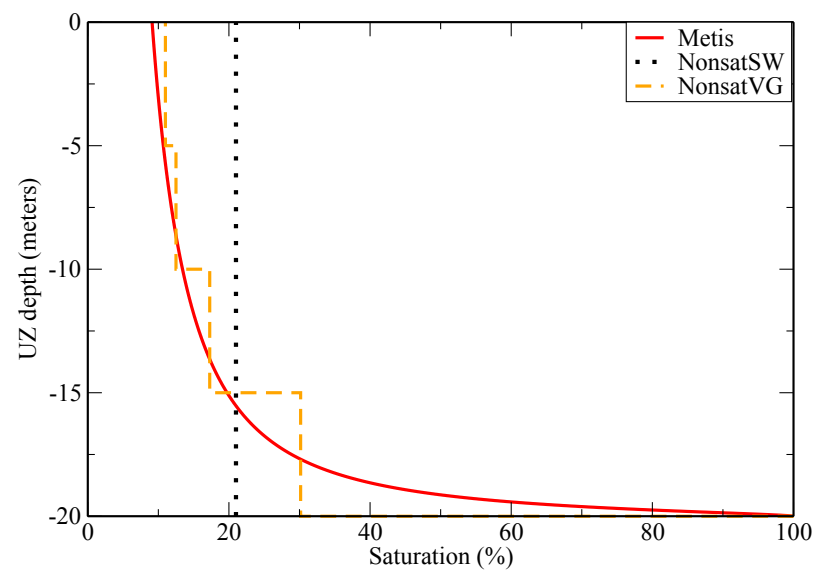

Figure 3: Evolution of the saturation with depth in Metis, NonsatVG and NonsatSW in a loamy unsaturated zone for a given set of parameters available in Table 2 .

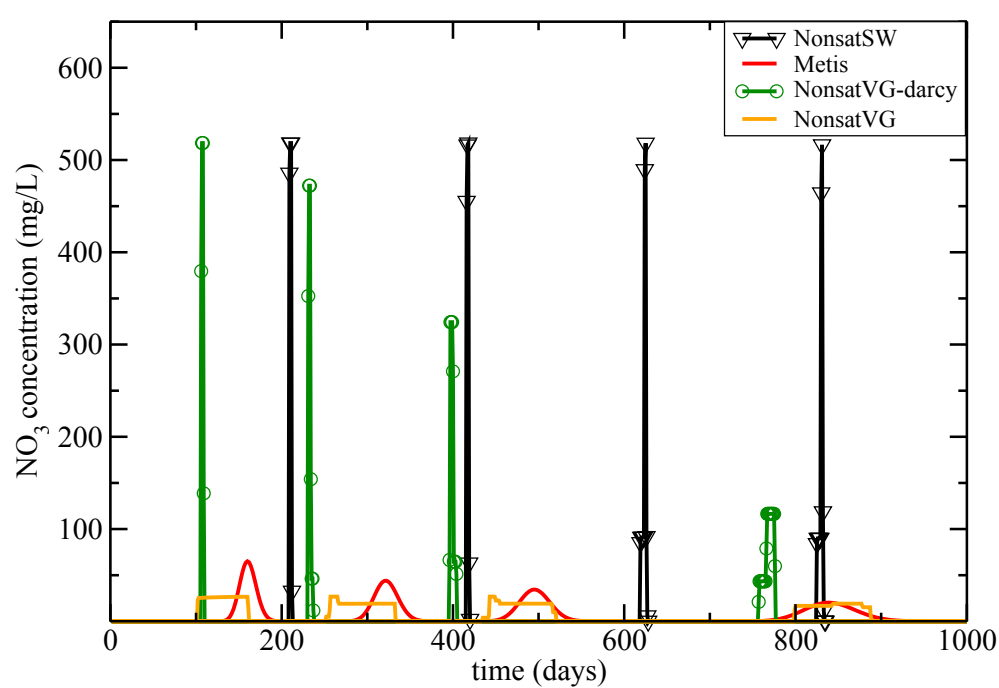

Figure 4: Transfer of passive solute in an ideal case at 4 depths (5, 10, 15 and $20 \mathrm{~m}$ ) through a loamy unsaturated zone column in Metis, NonsatSW, NonsatVG with only a Van Genuchten's saturation profile (NonsatVG-Darcy) and NonsatVG. 


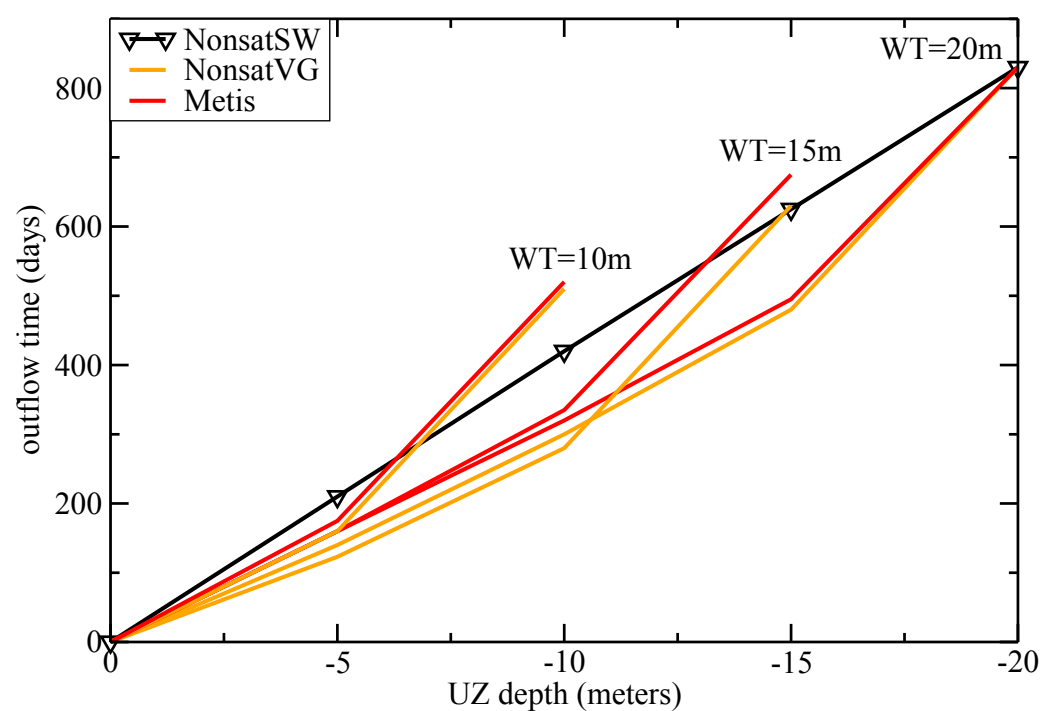

Figure 5: Time required for a passive solute to reach 4 depths $(5,10,15$ and $20 \mathrm{~m})$ depth in a loamy unsaturated zone for three different water table depths WT (m) in NonsatSW, NonsatVG and Metis. 


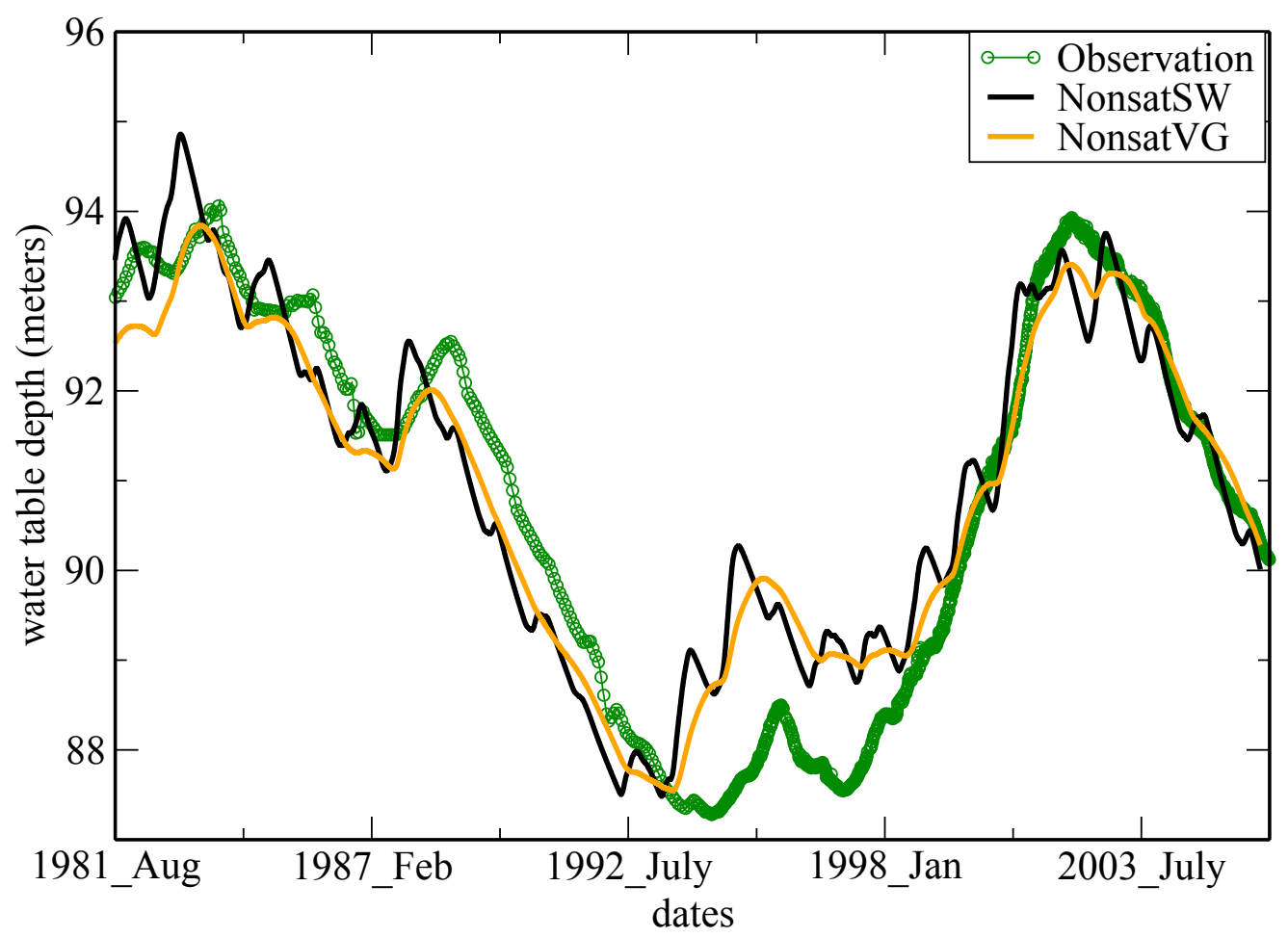

Figure 6: Comparison of the piezometric head observed at the Mainvilliers well and simulated by NonsatSW and NonsatVG, from 1981 to 2004. 


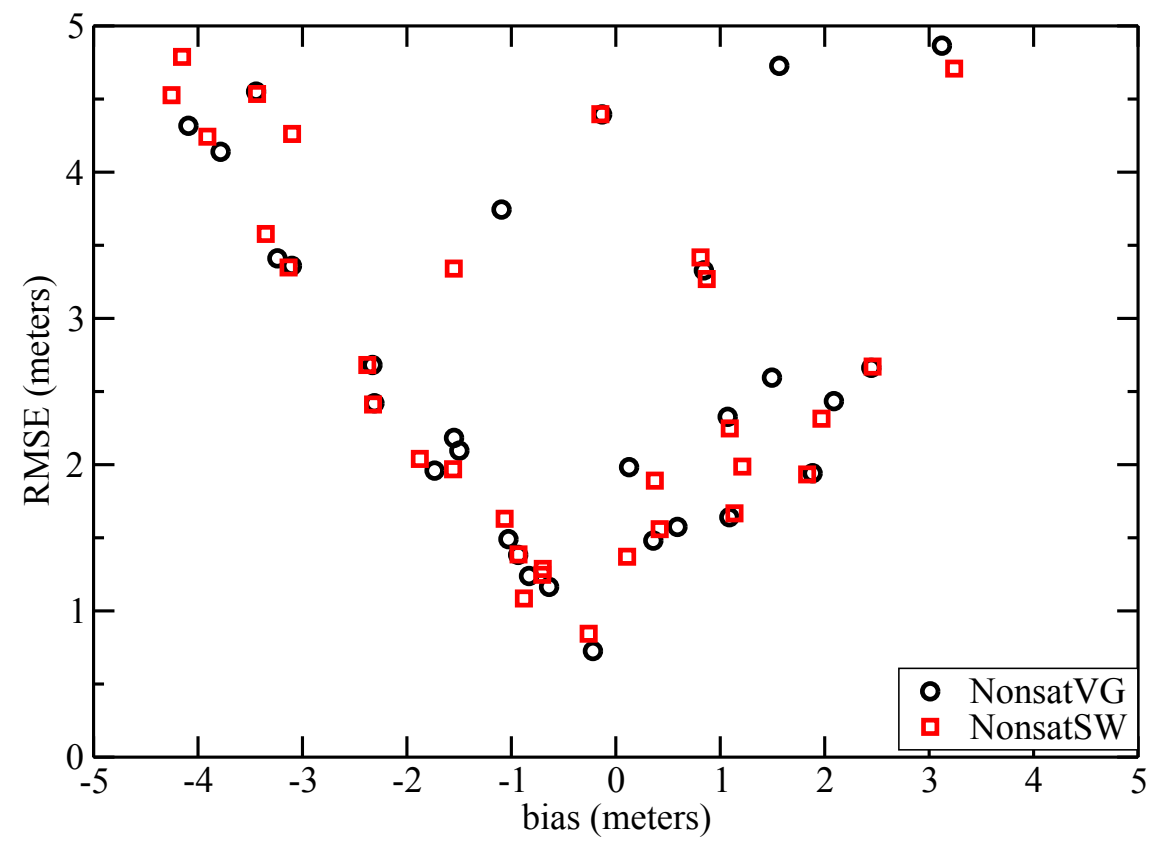

Figure 7: Root mean square error and bias in the modelling of water table fluctuation by NonsatSW and NonsatVG on 32 wells over the Seine basin, from 1981 to 2004. 

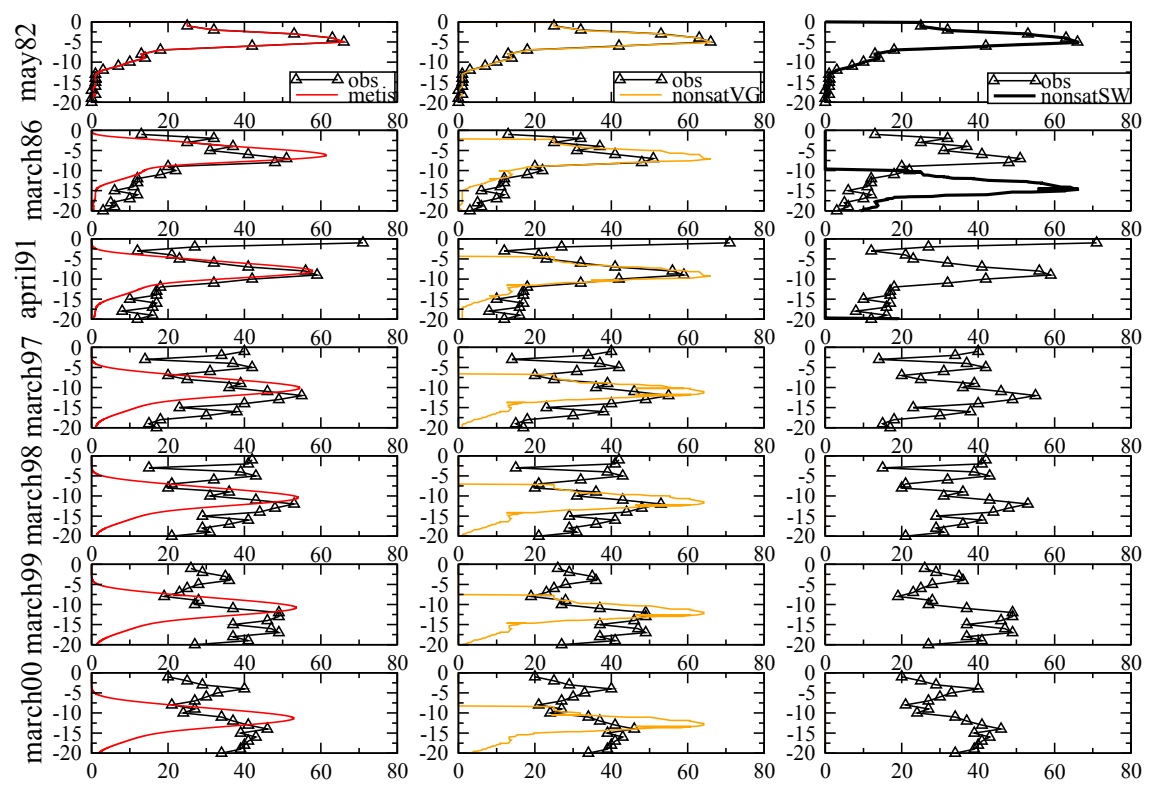

Figure 8: Nitrate concentration profile (x axis) in mg. $\mathrm{L}^{-1}$ observed at Haussimont from 1982 to 2000 in a 25 meters deep unsaturated zone (y axis) and simulated by Metis (left), NonsatVG (center) and NonsatSW (right). The modelling is performed by considering as initial conditions the nitrate profile observed in May 1982, with no additional solute input during the simulation. The water percolation flux is determined with the water balance module of the MODCOU model (Ledoux et al., 2007). 

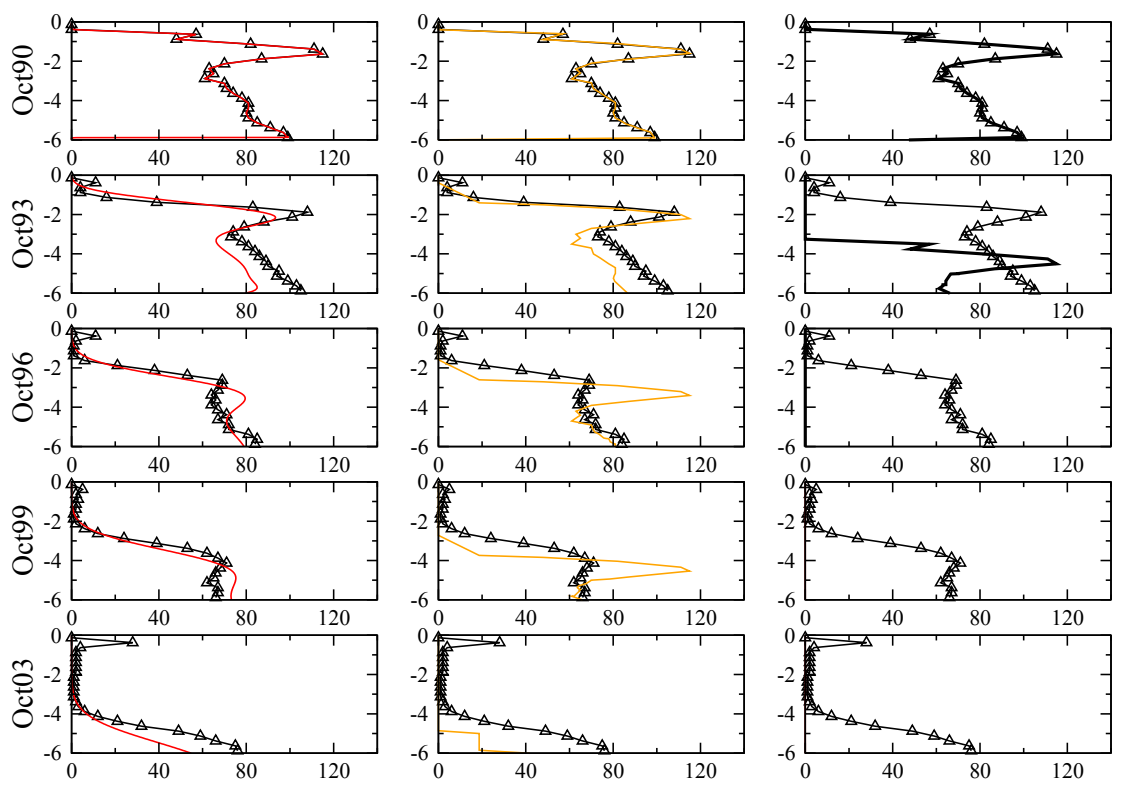

Figure 9: Nitrate concentration profile (x axis) in mg.L. $\mathrm{L}^{-1}$ observed at Thibie from 1990 to 2003 in a 15 meters deep UZ (y axis) and simulated by Metis (left), NonsatVG (center) and NonsatSW (right). The modelling is performed by considering as initial conditions the nitrate profile observed in October 1990, with no additional solute input during the simulation. The water percolation flux is determined with the water balance module of the MODCOU model (Ledoux et al., 2007). 


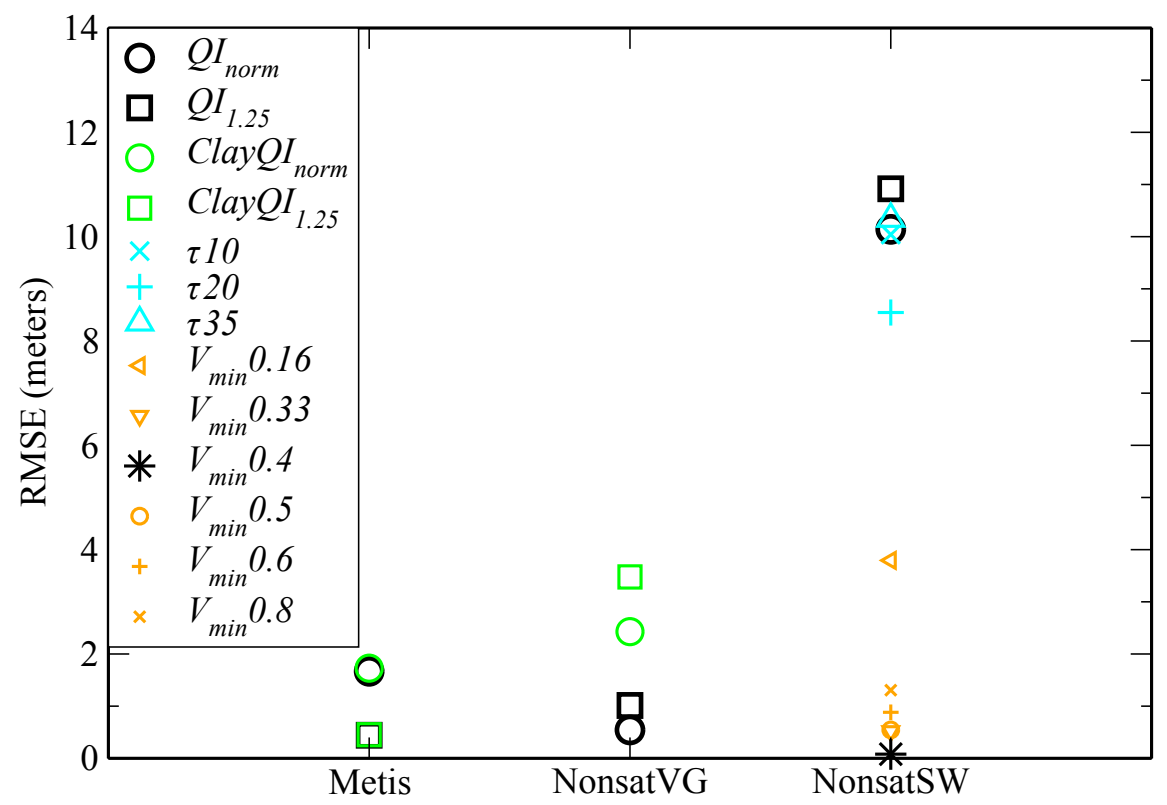

Figure 10: Root Mean Square Error (RMSE) of the nitrate peak depth simulated by NonsatVG, NonsatSW and Metis, from 1982 to 2000 at Haussimont. The results are obtained with the parameters defined in Table $4 . Q I_{\text {norm }}$ are obtained with infiltration determined from the water balance module of the MODCOU model (Ledoux et al., 2007). $Q I_{1.25}$ are obtained with a $25 \%$ larger infiltration flux. Clay are performed with clay class parameters (Table 1) with MODCOU infiltration $\left(\right.$ ClayQI $\left.I_{\text {norm }}\right)$ and a $25 \%$ larger infiltration $\left(C l a y Q I_{1.25}\right)$. With MODCOU infiltration, points $V_{\min } x$ are obtained with a minimal water volume value in each reservoir equal to $x(\mathrm{~m} / \mathrm{m})$ and points $\tau x$ are obtained with a $\tau=x$ days. 


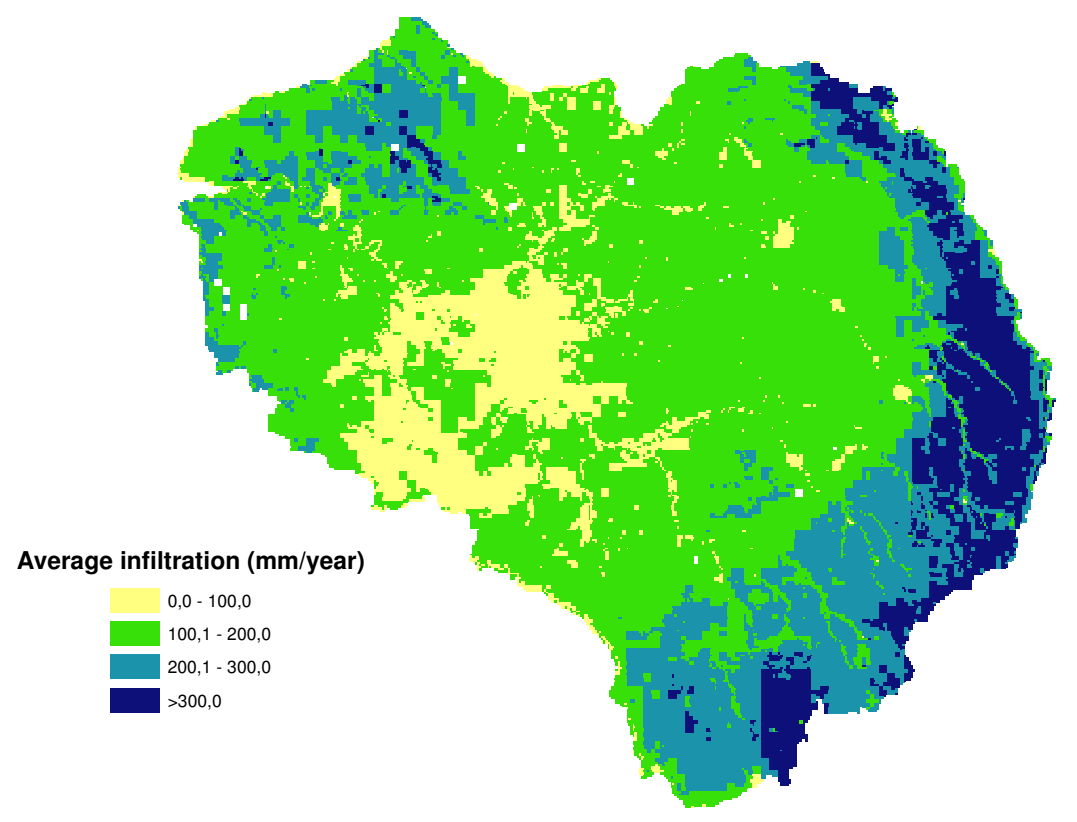

Figure 11: Average annual infiltration estimated from 1971 to 2006 over the Seine basin with the water balance module of the MODCOU model (Ledoux et al., 2007). 


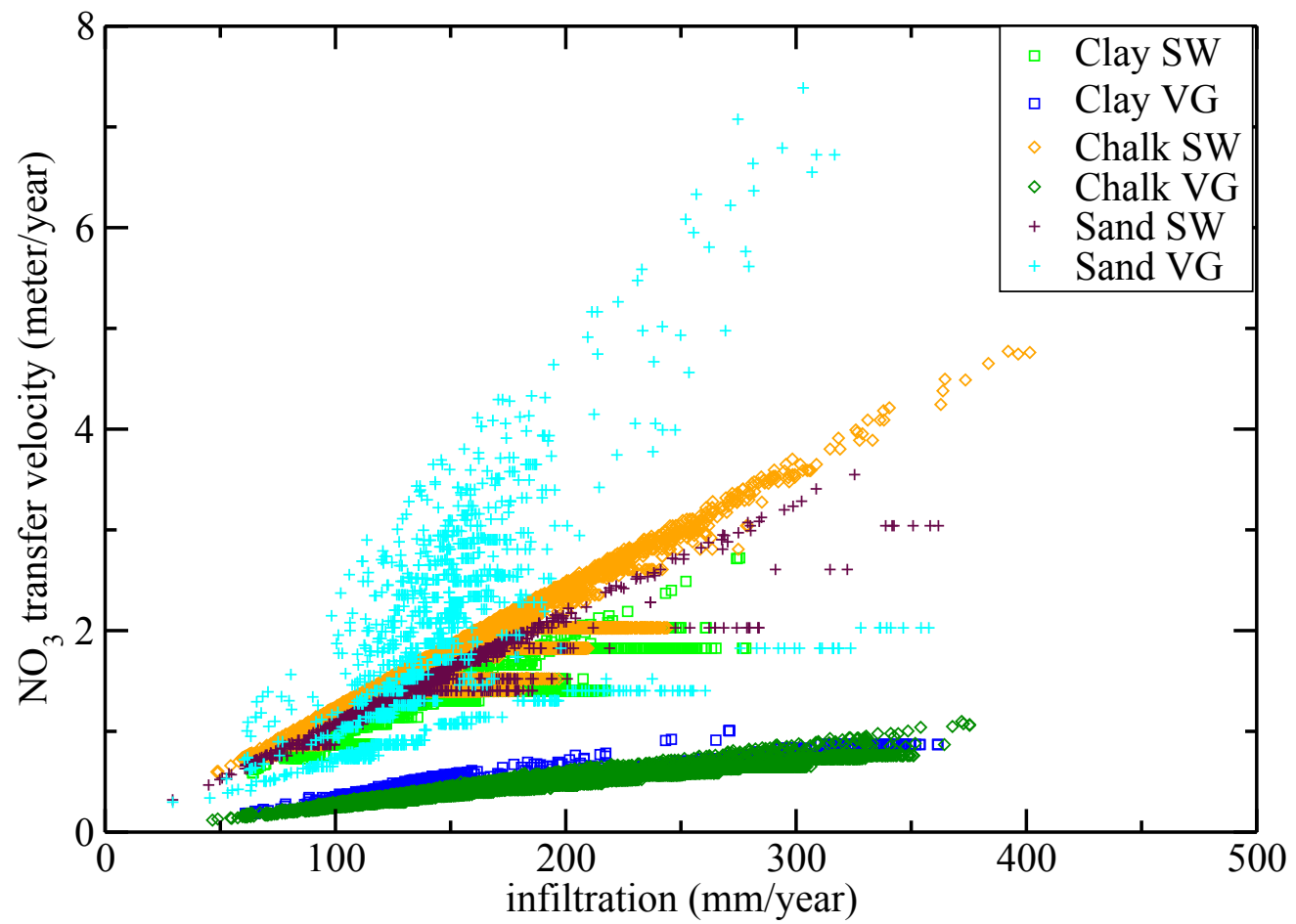

Figure 12: Comparison of the nitrate transfer velocity simulated by NonsatSW (SW) and NonsatVG (VG) for each cell located on chalk, clay and sandy soil types in the Seine basin, as a function of the average annual infiltration. 


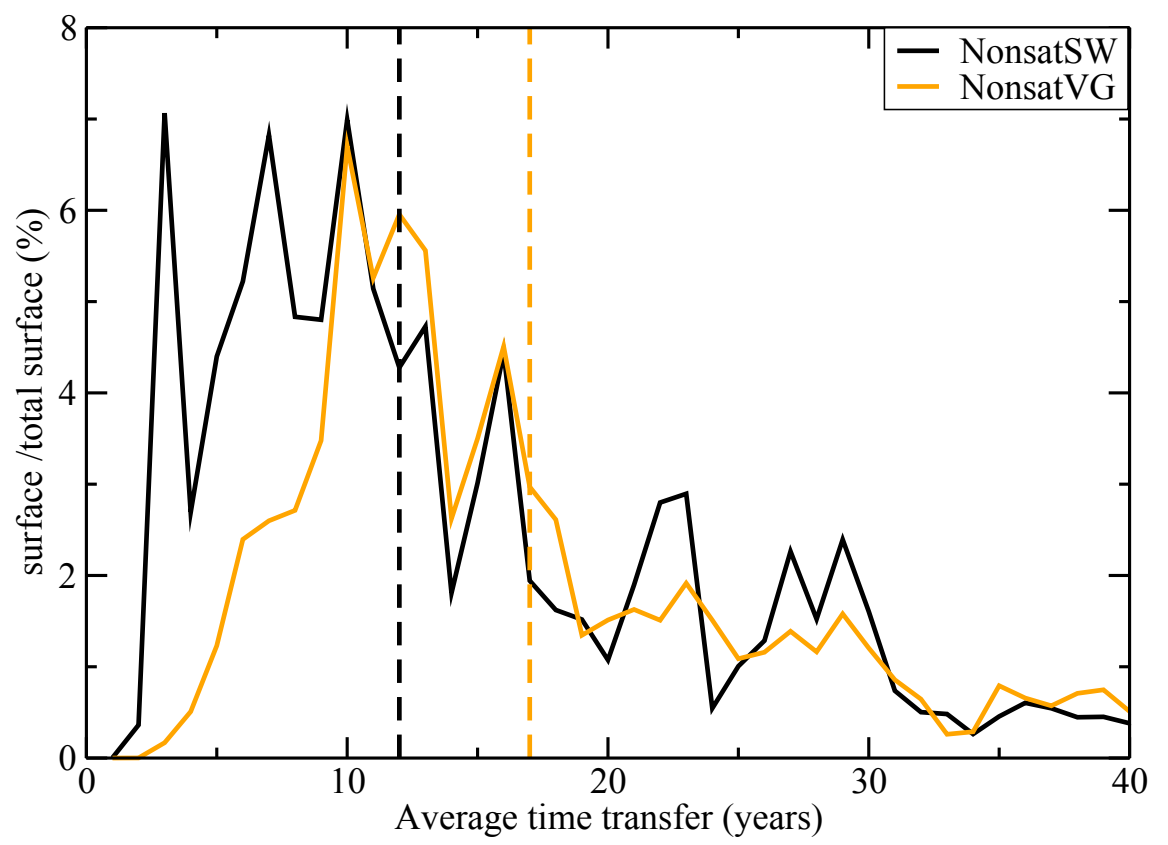

Figure 13: Surface repartition of the Seine basin depending on the average time required in years for an outflow of nitrate from the unsaturated zone to the saturated zone. The infiltration is determined with the water balance module of the MODCOU model (Ledoux et al., 2007) from August 1971 to August 2006 and a nitrate input occurs from the $181^{\text {th }}$ to the $196^{\text {th }}$ day of the simulation. At the dashed line, $50 \%$ of the unsaturated zone in the Seine basin have transferred nitrate to the saturated zone. 


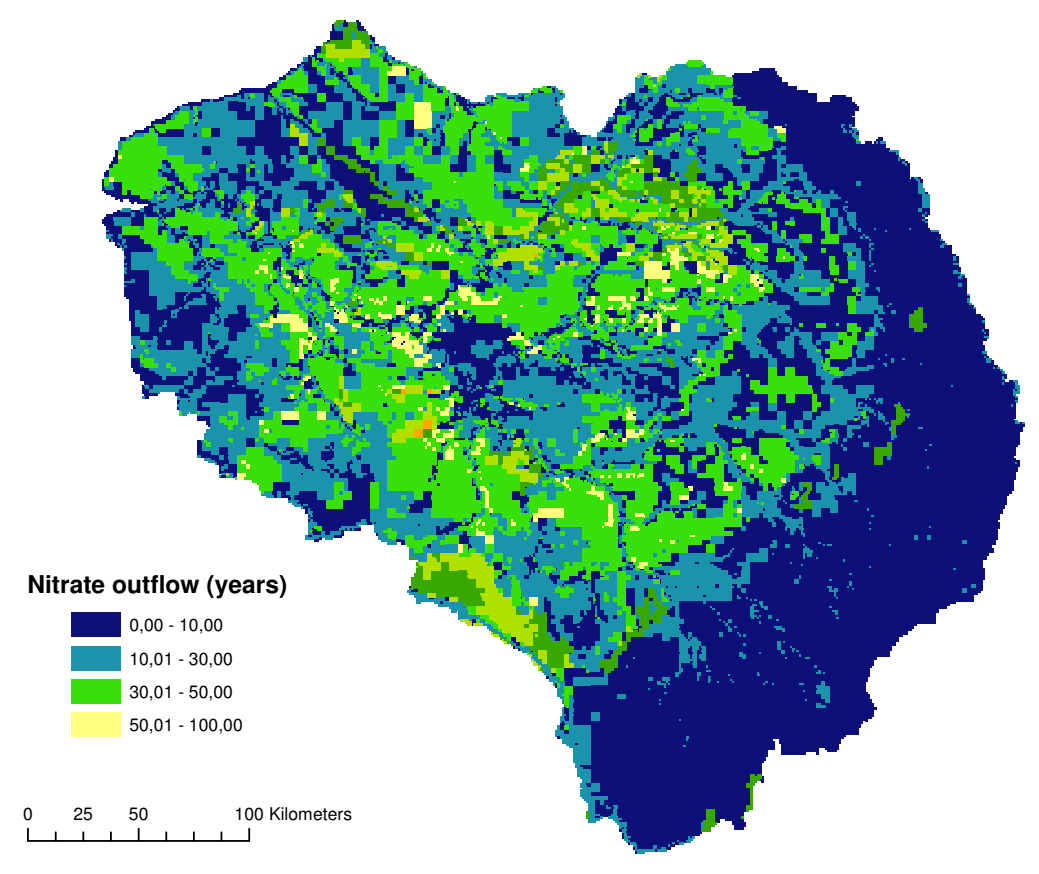

Figure 14: Average time required in years for a nitrate transfer through the unsaturated zone in the Seine basin with NonsatVG. The infiltration is determined with the water balance module of the MODCOU model (Ledoux et al., 2007) from August 1971 to August 2006 and a nitrate input occurs from the $181^{\text {th }}$ to the $196^{\text {th }}$ day of the simulation. 